\title{
ORIGINAL ARTICLE \\ Contribución al conocimiento de la distribución y estatus de la fauna quiropterológica de la Comunidad Autónoma de Cantabria
}

\author{
Raúl Molleda ${ }^{1, *}$, Isidoro Fombellida ${ }^{1}$
}

\begin{abstract}
Asociación Naturalista MUR calle Pablo Garnica, 85, 39300 Torrelavega, Cantabria, Spain.
\end{abstract}

* Corresponding author e-mail: mur.asonatur@gmail.com

DOI: https://doi.org/10.14709/ BarbJ.11.1.2018.04

Palabras clave: quirópteros, Cantabria, distribución, listado de especies, especies crípticas, captura en red, primeros datos.

Keywords: bats, Cantabria atonomous community, distribution, list of species, cryptic species, mist-netting, first data.

received: February, 09th 2018 accepted: July, 22nd 2018

\begin{abstract}
RESUMEN
Por primera vez se presenta una compilación extensa con información sobre la distribución de las especies de quirópteros localizadas en la Comunidad Autónoma de Cantabria (norte de España). Esta revisión se basa en datos propios con dos orígenes: tres temporadas recientes de muestreos con redes de niebla (2015-2017) complementado con análisis genético para la identificación de especies crípticas; y nuestra propia base de datos, con registros entre 1999 y 2017, obtenidos por observación directa (sobre todo en refugios), y detección ultrasónica. Los mapas de distribución se han completado con citas previamente publicadas por otros autores mencionados en el texto. Seis especies no habían sido reseñadas anteriormente en Cantabria: Myotis escalerai, Myotis of nattereri, Myotis alcathoe, Pipistrellus pygmaeus, Nyctalus lasiopterus y Nyctalus noctula. Otras dos solo lo habían sido en base a escasos restos óseos y una observación que se consideran dudosos: Myotis bechsteinii y Myotis mystacinus. Para muchos otros taxones, los datos publicados anteriormente fueron muy escasos. Además se ha identificado la subespecie Plecotus auritus begognae como presente en toda la región. Las especies localizadas ascienden a 25, de las que 16 muestran una distribución amplia, y las restantes restringida o poco conocida aún. Estos muestreos continúan realizándose.
\end{abstract}

\begin{abstract}
Distribution of bat species is given for first time for Cantabria Autonomous Community (northern Spain). This review is based on our own data from two different sources: three recent seasons of mist-netting (2015-2017) complemented with molecular analysis for cryptic species identification; and our own database, with records between 1999 and 2017, based on sighting (especially in bat roosts) and ultrasonic analysis. Distribution maps are completed with data previously published by other authors. Six species had not previously been documented in the region: Myotis escalerai, Myotis cf nattereri, Myotis alcathoe, Pipistrellus pygmaeus, Nyctalus lasiopterus and Nyctalus noctula. Two other species had only been formerly reported based on few skeletal remains of doubtful identification: Myotis bechsteinii and Myotis mystacinus. For many other taxa, previously published data were very scarce. The subspecies Plecotus auritus begognae has been identified as present throughout the region. Of the 25 species found, 16 show wide distribution, while the remaining present restricted distribution or they are little known. The samplings will have continuity.
\end{abstract}

\section{INTRODUCCIÓN}

Al igual que en otras regiones de la Península Ibérica, el conocimiento de los quirópteros que habitan la Comunidad Autónoma de Cantabria ha resultado tardío y restringido a las especies cavernícolas, pudiéndose distinguir tres etapas.

En las décadas de 1960 a 1980, Menéndez (1973), Tupinier (1982), y Meijide (1982) visitaron refugios subterráneos colectando especímenes y restos óseos, obteniendo así una primera visión de las especies cavernícolas. Sin embargo no cuantificaron poblaciones, lo que habría resultado muy útil para estimar su evolución. Además, algunas de sus identificaciones fueron posteriormente discutidas, como la presencia de Rhinolphus mehelyi y Myotis blythi; así como sus determinaciones de $M$. mystacinus y $M$. bechsteinii: Toca (2003a), Catálogo Regional de Especies Amenazadas de Cantabria (2008), F. González-Álvarez (com. pers.).

Una segunda etapa corresponde a las décadas de 1980 a 2000 , cuando se dio un salto cualitativo con los primeros muestreos con detectores de ultrasonidos con objetivo de proveer información para al Atlas de Vertebrados de Cantabria, proyecto del gobierno regional y la Universidad de Cantabria que finalmente no fue concluido ni publicado (F. González-Álvarez, com. pers.). Posteriormente, informes de impacto ambiental y documentos solicitados por la administración supusieron avances en el conocimiento 
puntual de la distribución de las especies ya conocidas, pero se trató de datos dispersos, poco accesibles, y cuyo reflejo en documentación publicada y cartografía resulta prácticamente nulo. Ver entre otros: González (2016), Fombellida et al. (2004), Fombellida \& Saiz (2009), Fombellida $(2005,2006,2012 a)$ y Saiz \& Fombellida (2006 y 2008). De este periodo, entre lo poco publicado hay que reseñar las aportaciones de Toca (2001, 2003a y 2003b).

Finalmente, una tercera etapa puede fijarse en los últimos años, cuando el número de especies identificadas y el grado de conocimiento de las mismas, aun teniendo lagunas, está experimentando un notable avance, y donde se inserta nuestra contribución. En esta publicación presentamos una revisión actualizada con información sobre la distribución de las especies de quirópteros localizadas en la Comunidad Autónoma de Cantabria, basada en tres temporadas recientes (2015-2017) de muestreos con redes de niebla, complementado con análisis genético para la identificación de especies crípticas, y el análisis de la propia base de datos con registros entre 1999 y 2017. Por falta de datos cuantitativos publicados no ha sido posible realizar un análisis de la evolución de poblaciones, ni tan siquiera para las especies cavernícolas. Respecto a las forestales, se trata de las primeras informaciones publicadas para la región.

\section{MATERIAL Y MÉTODOS}

\section{Area de estudio}

La Comunidad Autónoma de Cantabria se sitúa a 43으 de latitud en la costa del mar Cantábrico al norte de la Península Ibérica, con una extensión aproximada de 5.300 $\mathrm{km}^{2}$ (Fig. 1). Por su situación geográfica y su carácter montañoso y costero, este territorio presenta gran variedad de ambientes, hallándose en el límite entre las regiones biogeográficas mediterránea y eurosiberiana. Se distinguen tres áreas morfológicamente diferenciadas pero en suave transición: A) "La Marina", donde se concentra la mayor parte de la población humana, se corresponde con la franja litoral, estando dominada por prados con arbolado disperso, plantaciones de eucaliptos y áreas urbanizadas; B) "La Montaña", correspondiente a los relieves de la Cordillera Cantábrica, que discurre paralela a la costa y se eleva hasta 2.648 metros de altitud en los Picos de Europa, alternándose bosques caducifolios atlánticos de robles y hayas principalmente, con matorrales de sustitución de porte bajo y pastizales; C) los "Valles del Sur", en la cabecera de los ríos Ebro y Camesa (este último tributario del Duero), orientados al sur de la cordillera, de relieve más suave que la vertiente norte, con pastizales y bosques de robles en fase de recuperación. Así pues, la vegetación potencial se caracteriza por bosques eurosiberianos, excepto en enclaves del contacto con la región mediterránea, y también con una intrusión de bosques mediterráneos de carácter edáfico en cualquier zona.

Debido a la corriente del Golfo, Cantabria, al igual que el resto de la región cantábrica tiene unas temperaturas mucho más suaves que las que le correspondería por su latitud, con un clima templado oceánico húmedo, con veranos e inviernos suaves. Sin embargo, por su carácter montañoso, las temperaturas medias anuales varían entre los $14^{\circ} \mathrm{C}$ en la

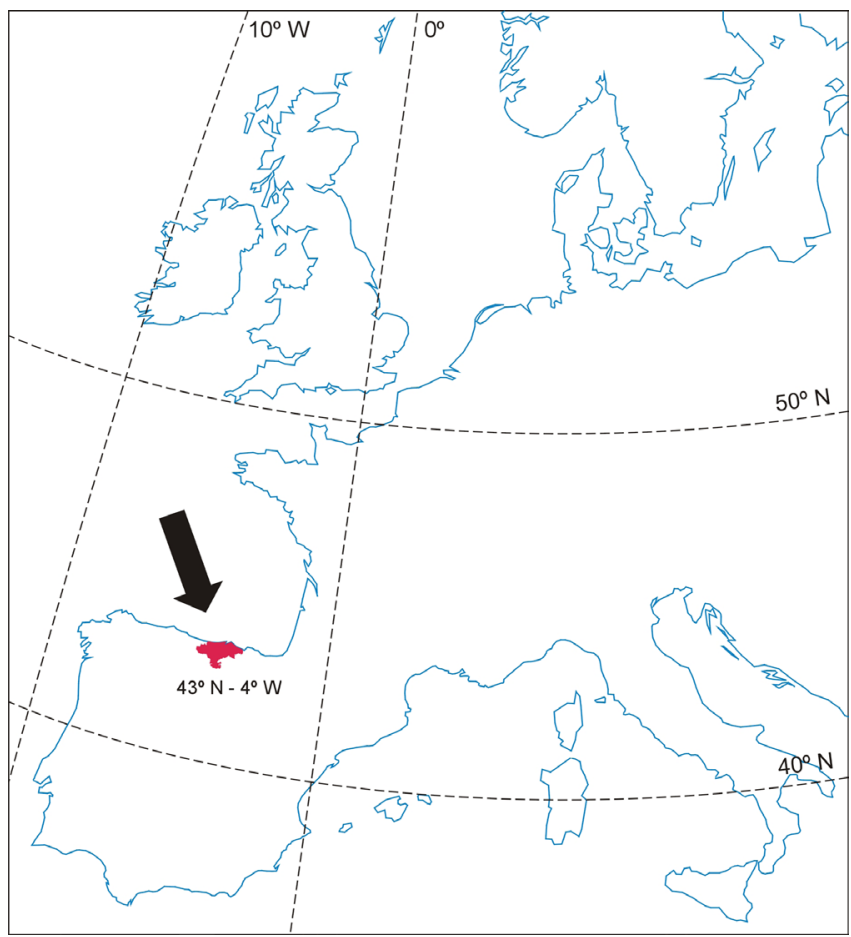

Fig 1 - Localización del área de estudio: Comunidad Autónoma de Cantabria, $5.300 \mathrm{~km}^{2}$. // Study área location: Cantabria Autonomous Community.

costa y los $3 \circ \mathrm{C}$ en las montañas más elevadas. Mientras que las precipitaciones se sitúan en torno a $1.200 \mathrm{~mm}$ anuales en la costa, aumentando los valores en las zonas montañosas hasta los $2.400 \mathrm{~mm}$, distribuidas con cierta regularidad a lo largo del año, lo que la sitúa en la denominada España húmeda.

\section{Capturas}

A partir de 2015, conscientes de la carencia de datos sobre especies fisurícolas, especialmente las forestales, así como de los taxones crípticos de reciente descripción, se realizaron trabajos de campo para completar el inventario y mejorar la cartografía de quirópteros en la Comunidad Autónoma de Cantabria, buscando tener un conocimiento equilibrado entre los diferentes grupos y taxones. Dichos trabajos han consistido en trampeos con redes de niebla y análisis genético, desarrollados entre 2015 y 2017.

Se han realizado 303 sesiones de muestreo, localizadas en 213 puntos en todo el ámbito regional (Fig. 2), ya que en 64 puntos se repitieron los muestreos entre dos y cinco veces en diferentes jornadas, estaciones y años. Esto último se reveló muy útil para detectar nuevas especies sucesivamente en un mismo punto. El tiempo efectivo de trampeo ha sido de 1.281 horas con 43 minutos. La longitud de redes dispuestas por noche ha variado entre 3 y 90 metros, con media de 19 metros, y un total acumulado de 5.936 metros. Las redes fueron de monofilamento y de poliéster, con medidas de 2, 3, 6, 9, 12 y 18 metros, con abertura de malla de 16 y $20 \mathrm{~mm}$. Los puntos seleccionados incluyeron bebederos, accesos a refugios, collados, y lugares de paso estimados en base a la configuración de la vegetación y la topografía, la mayor parte en ambientes de bosque autóctono maduro, ya que el estudio se orientó 
Lugares de muestreo con red

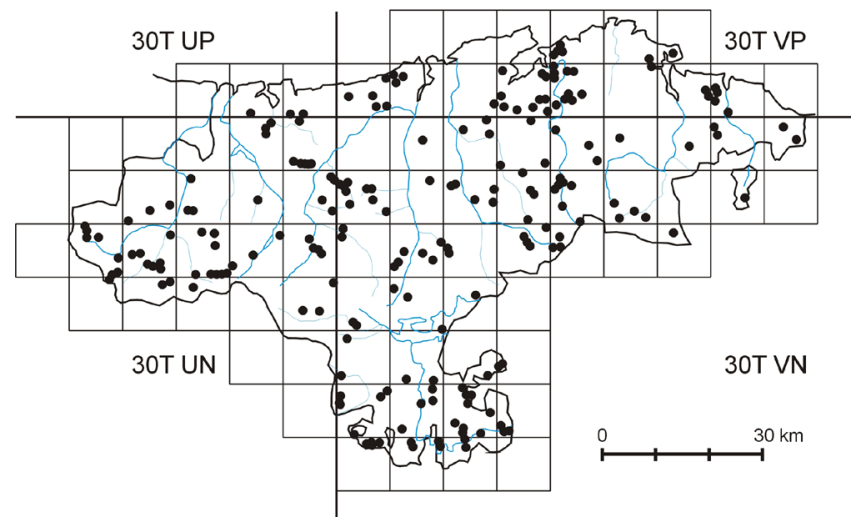

Fig. 2 - Lugares de muestreo con redes en Cantabria entre 20152017, $n=213$. // Mist-netting sampling locations in Cantabria Autonomous Community, $n=213$.

a especies fisurícolas forestales y crípticas, evitando en lo posible las cavernícolas y las accesibles por otros métodos. Otros puntos seleccionados para los muestreos fueron ojos de pequeños puentes, bebederos de ganado, remansos de arroyos, pistas forestales y huecos en muros de cabañas y edificios abandonados. En ocasiones se colocaron redes superpuestas hasta alcanzar una altura de $5 \mathrm{~m}$.

Los ambientes forestales muestreados cubrieron todos los tipos existentes en la región, si bien se priorizó aquellos de baja altitud y mayor madurez y complejidad estructural, como robledales de Quercus robur y Quercus pyrenaica. Ambientes de sustitución de los anteriores, como campiña donde alternan prados y cultivos con setos arbolados y arbustivos, también fueron objeto de estudio. Así como el arbolado de ribera, bien representado por situarse a menudo las redes en puntos de agua.

Los muestreos cubrieron 61 cuadros UTM de $100 \mathrm{~km}^{2}$, que suponen aproximadamente el $90 \%$ de la superficie de la Comunidad Autónoma.

Los individuos capturados se mantuvieron en bolsas de tela hasta su manipulación e identificación, que consistió en su reconocimiento específico (siempre que fue posible a partir de sus caracteres morfológicos), sexado, edad, y medición de la longitud de antebrazo y peso, siguiendo las especificaciones de Dietz \& Von Helversen (2004).

Acabado el procesamiento, que nunca duró más de 4 minutos, los murciélagos se liberaron en el lugar de captura, asegurándose que volaban libremente. En el caso de dudas de identificación (normalmente por pertenecer a un complejo críptico) se procedió a recoger biopsias de tejido alar para su posterior confirmación molecular, siguiendo el protocolo ético utilizado por el grupo de estudio de murciélagos de la EBD-CSIC. Las biopsias se tomaron en ambos dáctilo-patagios con bio-punch de $2 \mathrm{~mm}$, conservándose las muestras en viales con etanol al $70 \%$. La confirmación molecular se realizó posteriormente en el laboratorio de Ecología Molecular (LEM) de la EBD-CSIC. Para ello, se extrajeron en primer lugar los ácidos nucleicos normalmente mediante un protocolo de extracción salina. Una vez purificado el producto, se utilizó de molde para la amplificación de un marcador mitocondrial que, según los casos, consistió en un fragmento de los genes de citocromo " $b$ " o de alcohol deshidrogenasa (ND1) y cuyas secuencias se compararon con la librería de referencia del grupo de murciélagos de la EBD-CSIC (Ibañez et al. 2006). Para algunos casos (p.e. el complejo M.escalerai/M. cf. nattereri) el bandeado diferencial de una reacción de amplificación (PCR) diagnóstico, fue suficiente para la confirmación molecular sin precisarse secuenciación.

\section{Base de datos}

Nos referimos a la información que no procede de la campaña de capturas en red mencionada, sino de los datos recopilados por nosotros en campo desde 1999 hasta el presente, obtenidos por diferentes métodos, entre los que destacan la revisión de refugios con identificación por caracteres biométricos, y la identificación por ultrasonidos, tanto en refugios como en el exterior, a menudo una combinación de ambos métodos.

Se utilizaron detectores heterodinos Pettersson D230 (Elektronic, Suècia) y grabaciones en tiempo expandido con Batlogger de Elekon (Elekon, Suiza). Los análisis de sonogramas fueron realizados mediante el software Elekon Bat-Explorer (Elekon, Suiza). Como principales referencias para este análisis se ha seguido sobre todo Barataud (1995), Russo y Jones (2002), Obrist et al. (2004), y Barataud et al. (2015). Para la identificación de las grabaciones se consideró el tipo de pulso de ecolocación, las frecuencias de máxima energía, inicial y final, la amplitud de la señal, el intervalo entre pulsos, y la duración de los pulsos.

Se prefirió desechar registros ultrasónicos que no resultaran fiables y cuyas características acústicas se solaparan entre especies, considerándose suficiente el número de identificaciones fiables obtenido para cada especie. Algunas precauciones para evitar identificaciones dudosas han sido las siguientes: a) desechar los pulsos del género Rhinolophus con valores de máxima energía entre $106-107 \mathrm{kHz}$, para evitar el solapamiento entre $R$. euryale y $R$. hipposideros; b) desechar la identificación acústica para los géneros Myotis y Plecotus; c) considerar para $P$. nathusii solo pulsos sociales; d) para Pipistrellus pygmaeus pulsos de frecuencia casi constante entre $54-60 \mathrm{kHz}$; e) para Hypsugo savii solo pulsos entre $33-34 \mathrm{kHz}$;) para Eptesicus serotinus pulsos entre 26-27 kHz; g) para Nyctalus leisleri pulsos entre 22-23 kHz; h) para Nyctalus noctula solo pulsos entre 19-21 kHz con más de $18 \mathrm{~ms}$; i) para Nyctalus lasiopterus identificar solamente por observación directa combinada con pulsos alternos $15-16 \mathrm{kHz}$; Tadarida teniotis fue separado en escuchas directas de Nyctalus lasiopterus/noctula por su regularidad temporal en los pulsos de ecolocación, valores de frecuencia bajos por debajo de $13 \mathrm{kHz}$, y ausencia de alternancia de señales de frecuencia constante y modulada.

Cualquier identificación biométrica que no afinara hasta el nivel específico tampoco fue considerada. Precauciones en este sentido fueron, por ejemplo: a) en el caso del género Rhinolophus en refugios, siempre se tomó como mínimo la medida del antebrazo; b) la identificación del género Plecotus se hizo siempre sobre ejemplares en mano o por análisis genético. La identificación visual directa dentro de sus refugios ha sido útil en el caso de colonias bien conocidas 
durante años, por ejemplo para Myotis myotis, Myotis emarginatus y Miniopterus schreibersii. La combinación de escuchas en heterodino con observación crepuscular o mediante foco, ha resultado igualmente satisfactoria para algunos taxones, como por ejemplo $M$. daubentonii cazando rasante sobre el agua.

\section{Presentación de datos}

La presentación de los resultados en esta revisión se hace especie por especie incluyendo la distribución, frecuencia estimada, y tipología de los refugios y hábitats utilizados, acompañado de mapas de distribución, así como la cronología de las citas cuando ello se considera relevante. Otros rasgos biológicos, ecológicos, de conservación y evolución de las poblaciones, tienen su comentario cuando se ha dispuesto de dicha información para especies concretas. Los mapas de distribución de cada especie en Cantabria, referidos a la cuadrícula UTM de $100 \mathrm{~km}^{2}$, se han trazado en base a tres fuentes de información: nuestras capturas en red (2015-2017), con análisis genético en los casos requeridos; nuestra base de datos; otras fuentes citadas en el texto, solo para aquellos cuadros que no fueran cubiertos por nuestras observaciones. Ver modelo de estos mapas en la figura 3.

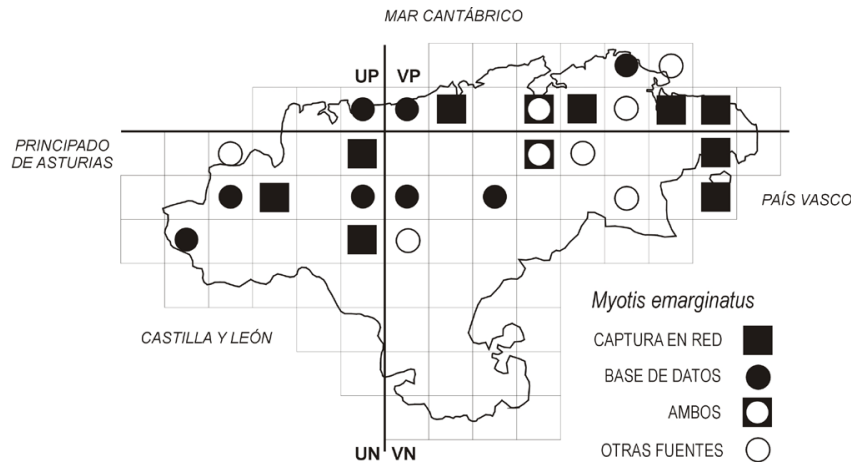

Fig. 3 - Modelo de mapa de distribución de los diversos taxones en Cantabria. Ver detalles en el texto. // Model of the distribution maps of the various taxa found in Cantabria, used in this paper. Maps are referred to the $100-\mathrm{km}^{2}$ UTM grid, and have been drawn up based on three sources of information: our own mistnetting (2015-2017), with genetic analysis in the required case (black squares); our database with acoustic detection and direct observation; other sources cited in the text, only for those squares that were not covered by our own observations.

\section{RESULTADOS Y DISCUSIÓN}

El número de ejemplares de quirópteros capturados ha sido de 1.740 pertenecientes a 21 especies. El análisis genético se ha extendido en ocasiones a especies no crípticas para su caracterización genética, siendo el número total de biopsias realizado de 564, y de análisis hasta el momento 271. Por otra parte, los registros extraídos de nuestra base de datos suman 2.483 correspondientes a 20 especies. En total, 25 especies han sido identificadas en Cantabria. La tabla 1 muestra el número y modo de obtención de los registros para cada especie utilizados en el presente trabajo. Para 6 especies solo se consideran los ejemplares analizados en mano por captura en red, y para las crípticas, solo las identificaciones por DNA.

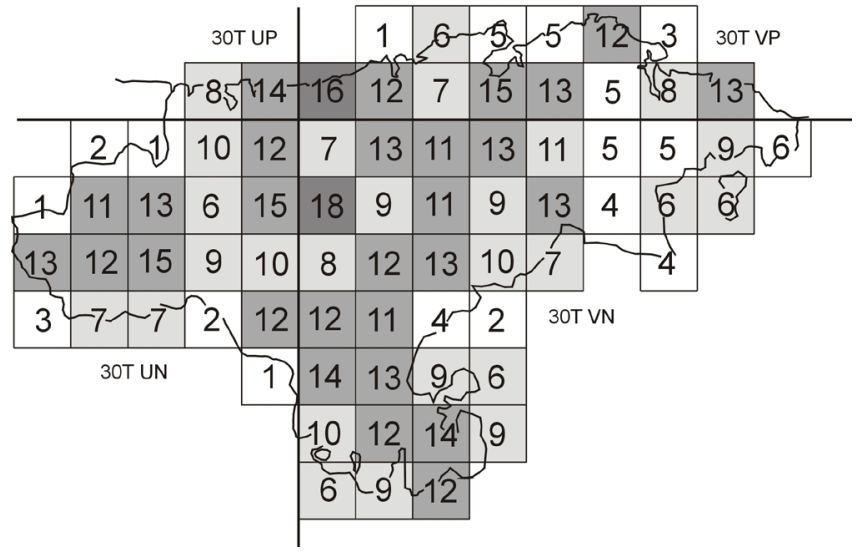

Fig. 4 - Riqueza en especies de quirópteros en Cantabria hasta la fecha por cuadros UTM de $100 \mathrm{~km}^{2}$ (solo datos propios). // Bat species richness found in Cantabria to date (only own data).

El mapa de la figura 4 muestra el número de especies localizadas en Cantabria por cuadros UTM de $100 \mathrm{~km}^{2}$. Dichos valores dependen aún en gran medida de la intensidad de muestreos realizados entre las diferentes zonas, siendo de esperar que para muchos cuadros, los valores se incrementen en la medida en que se intensifiquen en ellos los muestreos.

\section{Murciélago de herradura grande Rhinolophus ferrumequinum Schreber, 1774}

Las referencias de las décadas de 1960 a 1980 lo señalan como abundante y bien distribuido. Meijide (1982) consideraba $R$. ferrumequinum como "muy abundante, ubiquista y poco exigente", anotando en su catálogo 106 cavidades subterráneas y 5 edificaciones donde se hallaba presente. Desafortunadamente no aportaba otra información que pudiera ser útil en adelante para evaluar la evolución de sus poblaciones, como número de ejemplares presentes en los refugios, periodo de ocupación de los mismos, o indicios de reproducción. Por su parte, Menéndez (1973) citaba la presencia de un número elevado (aunque no precisado) de ejemplares hibernando en la Cueva del Calero (también Cueva Rogeria), actualmente declarada LIC, en la que en los últimos años solo hemos observado uno o ningún ejemplar en época invernal.

La evolución de muchos de los refugios citados por ambos autores no ha sido buena, desapareciendo o reduciéndose las colonias, como hemos comprobado al revisar treinta años después 30 cavidades y tres edificios entre los citados por Meijide (1982) en su catálogo. De hecho, en 16 cuevas se instalaron rejas o puertas para proteger yacimientos arqueológicos, por su dedicación al turismo, o para captación y suministro de agua; en 8 constatamos reducciones o ausencia de ejemplares, asociados a perturbaciones y deterioros diversos, sobre todo por incursiones recurrentes de grupos espeleológicos, empresas turísticas y simples curiosos; 2 cuevas fueron destruidas por canteras; y los tres edificios mencionados fueron rehabilitados, excluyendo a las colonias que albergaban. Solamente no resultaron afectadas las cuatro restantes cavidades. 
Tabla 1 - Número de registros de quirópteros en la Comunidad Autónoma de Cantabria, ordenados por especies y referidos a los métodos de obtención. // Number of own records of bats in the Autonomous Community of Cantabria, sorted by species and referred to data collection methods.

\begin{tabular}{|c|c|c|c|c|c|c|c|}
\hline & $\begin{array}{l}\text { Análisis } \\
\text { genético }\end{array}$ & $\begin{array}{l}\text { Análisis } \\
\text { ultrasonido }\end{array}$ & $\begin{array}{l}\text { Escucha } \\
\text { ultrasonido }\end{array}$ & Escucha + visual & En mano & Visual & Total \\
\hline Rhinolophus ferrumequinum & 0 & 10 & 50 & 67 & 112 & 0 & 239 \\
\hline Rhinolophus hipposideros & 0 & 8 & 23 & 63 & 86 & 0 & 180 \\
\hline Rhinolophus euryale & 0 & 13 & 0 & 16 & 15 & 0 & 44 \\
\hline Myotis myotis & 6 & 0 & 0 & 0 & 9 & 15 & 30 \\
\hline Myotis bechsteinii & 2 & 0 & 0 & 0 & 11 & 0 & 13 \\
\hline Myotis daubentonii & 30 & 16 & 0 & 90 & 98 & 0 & 234 \\
\hline Myotis escalerai & 5 & 0 & 0 & 0 & 0 & 0 & 5 \\
\hline Myotis cf nattereri & 80 & 0 & 0 & 0 & 0 & 0 & 80 \\
\hline Myotis emarginatus & 1 & 0 & 0 & 6 & 20 & 2 & 29 \\
\hline Myotis alcathoe & 41 & 0 & 0 & 0 & 58 & 0 & 99 \\
\hline Myotis mystacinus & 7 & 0 & 0 & 0 & 0 & 0 & 7 \\
\hline Pipistrellus pipistrellus & 22 & 46 & 218 & 846 & 638 & 0 & 1770 \\
\hline Pipistrellus pygmaeus* & 0 & 6 & 0 & 0 & 0 & 0 & 6 \\
\hline Pipistrellus kuhlii & 0 & 17 & 27 & 319 & 16 & 0 & 379 \\
\hline Pipistrellus nathusii* & 0 & 7 & 0 & 0 & 0 & 0 & 7 \\
\hline Hypsugo savii & 1 & 15 & 26 & 6 & 46 & 0 & 94 \\
\hline Eptesicus serotinus & 0 & 20 & 68 & 103 & 21 & 0 & 212 \\
\hline Nyctalus leisleri & 30 & 23 & 31 & 20 & 175 & 0 & 279 \\
\hline Nyctalus lasiopterus & 2 & 5 & 20 & 5 & 6 & 0 & 38 \\
\hline Nyctalus noctula* & 0 & 5 & 0 & 0 & 0 & 0 & 5 \\
\hline Barbastella barbastellus & 9 & 16 & 18 & 20 & 54 & 8 & 125 \\
\hline Plecotus auritus & 31 & 0 & 0 & 4 & 95 & 0 & 130 \\
\hline Plecotus austriacus & 4 & 0 & 0 & 0 & 51 & 0 & 55 \\
\hline Miniopterus schreibersii & 0 & 0 & 5 & 11 & 54 & 24 & 94 \\
\hline Tadarida teniotis & 0 & 12 & 54 & 2 & 0 & 0 & 68 \\
\hline Totales & 271 & 219 & 540 & 1578 & 1565 & 49 & 4222 \\
\hline
\end{tabular}

Posteriormente González (2016), en un documento solo parcialmente publicado para la gestión de la Red Natura 2000, cita la revisión de 53 cavidades subterráneas, hallándolo presente en el $66 \%$ de ellas. En algunas de estas cavidades, el mismo autor (com. pers.) nos ha referido la presencia de grandes colonias que, por el número de ejemplares que albergaban, debían ser relevantes para el mantenimiento del estatus de la especie en la región, si bien igualmente afectadas por impactos graves. Así, una de ellas, con cientos de ejemplares en hibernación, tiene sobre ella una cantera en explotación que pudiera haber causado ya su desaparición. Mientras que otra cueva de hibernación, con decenas o cientos de individuos, carece de medidas de protección. Finalmente, concluye que el $43,8 \%$ de las cavidades habitadas por $R$. ferrumequinum se muestran vulnerables frente a las presiones antrópicas, mientras que el $52,2 \%$ restante las evalúa como no vulnerables, hecho que le permite afirmar que la especie se halla en un estado de conservación favorable en Cantabria. Sin embargo, si nos atenemos al cumplimiento de las medidas de gestión planteadas en su estudio, ninguna ha sido asumida hasta el momento por la Administración, excepto ciertos censos de individuos en algunas de las colonias, y el desbroce eventual de sus entradas (F. González-Álvarez, com. pers.).

Relativo a nuestros datos (Tabla 1), aportamos aquí 239 registros de 152 localidades distribuidas por la mayor parte de la superficie de la Comunidad Autónoma, en altitudes entre el nivel del mar y 1105 m s.n.m., si bien en cotas altas se detecta menor frecuencia. Relativo a sus refugios, hemos observado a la especie en 50 cavidades subterráneas (57\%) y 37 edificios (43\%). En el $51 \%$ de los casos se trató de ejemplares solitarios; el 33\% fueron grupos entre dos y diez ejemplares; y en el $16 \%$, grupos de más de diez individuos ubicados en 11 refugios, entre los que destacan: una agrupación de 282 en un pajar en periodo post-reproductor; 95 ejemplares en periodo previo a la reproducción en una nave ganadera abandonada; 71 individuos en el mismo periodo en un molino fluvial abandonado; y un mínimo de 51 saliendo de un viejo palacio en plena temporada de reproducción; así como varias decenas en un abrigo que ocupan en primavera. Como se ve, los edificios resultan más 
relevantes para las grandes agrupaciones estivales, mientras las cavidades subterráneas recogen ejemplares dispersos o en pequeños grupos, así como fuera de la época estival.

Ejemplares alejados de sus refugios se han localizado con poca frecuencia mediante detectores ( $25 \%$ de los registros) probablemente debido a la corta distancia de detección por ultrasonidos, y con mayor frecuencia entre los ejemplares capturados (57\%). En un muestreo para obtener índices kilométricos de contactos realizado en la franja costera de Cantabria (Fombellida 2012b) se obtuvo un valor de 0,04 contactos $/ \mathrm{km}$, muy bajo respecto a 6,74 contactos $/ \mathrm{km}$ para el conjunto de las especies detectadas.

Por último, precisar que en nuestros muestreos con redes de niebla, una gran parte de los cuales se desarrolló en zonas lejos de sus refugios, capturamos 66 individuos en 35 localidades del total de 212 muestreadas (Fig. 5), de los que 34 eran hembras, 24 machos y ocho no sexados. De las hembras, 13 mostraban signos de estar reproduciéndose. Indicios de reproducción los hemos hallado en todo el área, tanto hembras con crías al pecho, como lactando.

Si bien se comprueba que $R$. ferrumequinum se encuentra con frecuencia, y ampliamente distribuido en Cantabria, tanto en sus refugios como en el exterior, las referencias previas tanto orales como escritas (Menéndez 1973, Meijide 1982, Tupinier 1982, González 2016) lo citaban en un mayor número de refugios y con mayor abundancia que en la actualidad, lo que podría ser indicativo de un declive. El sostenimiento de su población actual depende, a nuestro parecer, de la abundante dispersión de construcciones apropiadas para su refugio en el medio rural, así como cavidades subterráneas en las abundantes formaciones calizas de la región, y de hábitats bien conservados repartidos de manera uniforme, sin discontinuidades amplias entre comarcas, excepto las extensas plantaciones de eucaliptos y zonas urbanas en la franja costera que no le son favorables. No obstante, unas mínimas medidas de conservación son necesarias para prevenir su aparente declive, enfocadas especialmente a la conservación de sus colonias en cavidades subterráneas y edificios.

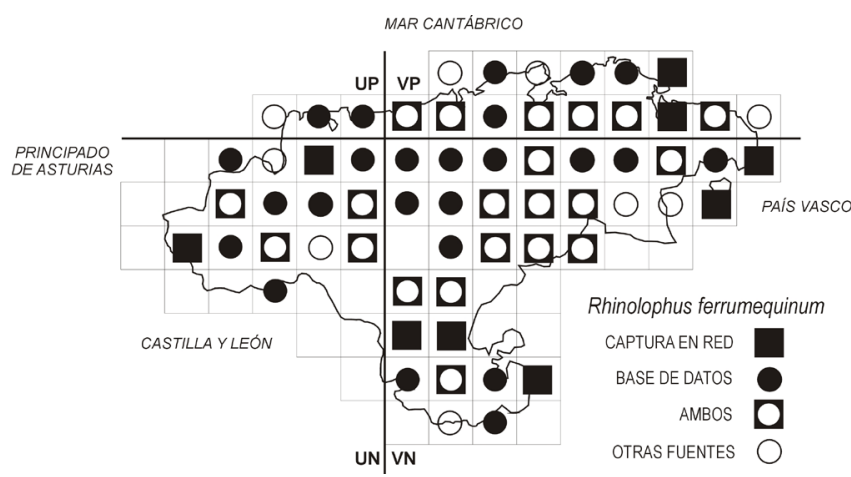

Fig. 5 - Distribución de Rhinolophus ferrumequinum en Cantabria según cuadrícula UTM de $100 \mathrm{~km}^{2}$. // Distribution of Rhinolophus ferrumequinum according to $100-\mathrm{km}^{2}$ UTM grid.

\section{Murciélago de herradura pequeño Rhinolophus hipposideros Bechstein, 1800}

Información previa a la nuestra se encuentra en Meijide (1982) que en su catálogo de refugios lo consideraba "frecuente", citando 15 cavidades subterráneas y seis construcciones con presencia, número sin embargo muy inferior a los 111 refugios que aporta para $R$. ferrumequinum. En nuestros registros la desproporción es menor, con 66 refugios localizados para $R$. hipposideros frente a 98 para $R$. ferrumequinum, lo que creemos se debe al hecho de haber revisado mayor número de construcciones. En efecto, comprobamos cómo $R$. hipposideros ocupa en mayor medida edificios que cuevas en la región (79\% frente a $21 \%$ según nuestros datos) si bien, debido a la inaccesibilidad de muchas propiedades privadas para el investigador, las colonias en edificios resultan sin duda subestimadas para ambos taxones.

A pesar de su ocurrencia en habitáculos de similares características, resulta llamativa la escasa proporción de refugios compartidos entre ambas especies según nuestras observaciones: solo 22 de un total de 116 examinados (19\%). Hasta qué punto ello se debe a interacciones excluyentes, o a la preferencia de $R$. hipposideros por construcciones se desconoce.

De los 21 refugios citados por Meijide (1982) hemos revisado siete treinta años después, todos ellos probablemente perdidos para la especie en la actualidad: cinco son cuevas en las que se han instalado rejas excluyentes para proteger yacimientos arqueológicos; otro es un edificio ahora rehabilitado; y el restante, una cueva en la que no hemos hallado nunca un ejemplar.

González (2016) solo lo halló en el $28 \%$ de las cavidades prospectadas (frente al $66 \%$ de $R$. ferrumequinum y el $62 \%$ de $R$. euryale), y de hecho, admite no poder valorar adecuadamente su población al no considerar refugios en construcciones y en pequeñas cavidades (no solo en grandes cuevas), clasificando su población en estado desfavorable.

Nuestras observaciones (180) corresponden a 116 localidades distribuidas por la mayor parte de la superficie regional (Fig. 6), entre el nivel del mar y 1280 m s.n.m., con mayor presencia en cotas altas que $R$. ferrumequinum. De 59 refugios donde fue identificado, 26 eran ocupados por individuos solitarios, 19 por grupos de dos a diez ejemplares, y siete por grupos mayores entre 15 y 100 individuos. En los siete restantes se hallaron hembras con crías (casi siempre solitarias), y cadáveres.

De los 71 ejemplares capturados en 29 localidades, la mayoría lo fueron cerca de sus refugios, resultando 35 hembras, 21 machos y 15 no sexados. De las hembras, ocho mostraban signos de reproducción.

Los hábitats donde se ha detectado han resultado muy diversos, abarcando todo tipo de arbolado, donde particularmente explotan los linderos y caminos, desde hayedo a encinar, así como todo tipo de robledales y riberas. Zonas de campiña, pastizales y matorral también fueron frecuentados. El índice de abundancia de ejemplares obtenido en itinerarios con detector en la franja costera de 
Cantabria (Fombellida 2012b) es similar al obtenido para $R$. ferrumequinum, con un valor bajo de 0,03 ejemplares/ $\mathrm{km}$, debido en buena parte a su escasa detectabilidad por ultrasonidos.

El Murciélago de herradura pequeño se encuentra por lo tanto distribuido por toda Cantabria, resultando quizá más frecuente en el interior, en el Alto Ebro y el valle de Liébana, donde se localizan con facilidad colonias en cada aldea, ubicadas en viejos edificios. Precisamente el uso que hace de construcciones, con una menor dependencia de cavidades, puede hacer que no se vea tan perjudicado como los otros rinolofos por el deterioro y cierre de cuevas.

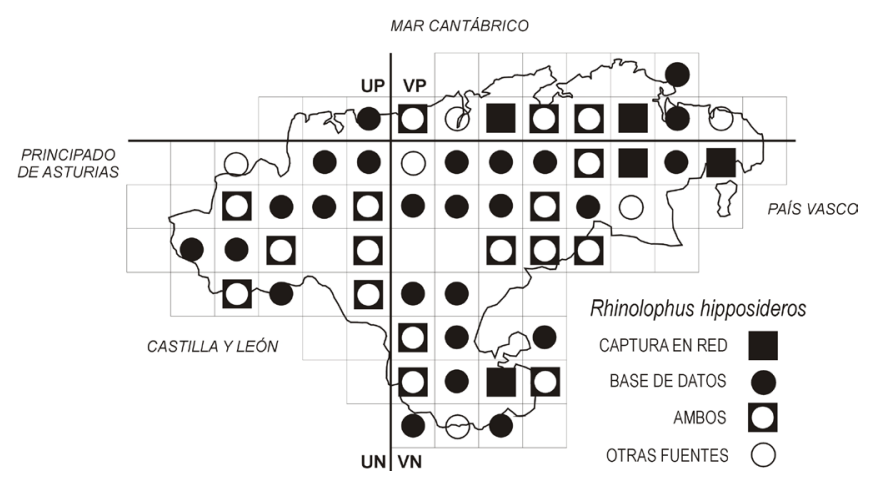

Fig. 6 - Distribución de Rhinolophus hipposideros en Cantabria según cuadrícula UTM de $100 \mathrm{~km}^{2}$. // Distribution of Rhinolophus hipposideros according to $100-\mathrm{km}^{2}$ UTM grid.

\section{Murciélago de herradura mediterráneo Rhinolophus euryale Blasius, 1853}

Menéndez remitió a Tupinier (1982) para su identificación unos huesos hallados en la Cueva del Calero que fueron identificados como pertenecientes a este taxón. Más tarde Meijide (1982) cita 22 cavidades subterráneas con presencia, pero reconociendo posibles errores de identificación por confusión con $R$. ferrumequinum. Entre dichas cavidades hemos revisado ocho, de las cuales cinco se hallan cerradas en la actualidad con rejas infranqueables para quirópteros con objeto de proteger yacimientos arqueológicos y para captación de agua; otras dos acogen un reducido número de ejemplares; mientras que en la restante no hemos observado ejemplares.

Ya en la década de 1990, los mapas preparados para el Atlas de Vertebrados de Cantabria (no publicado) lo mostraban presente en un $25 \%$ del territorio, principalmente en la franja costera y el sector calizo oriental. Posteriormente González (2016), a quien se debe la mayor contribución sobre la distribución de esta especie en la región, refiere varias colonias con centenares de ejemplares y grupos menores, repartidos por cavidades subterráneas de cotas bajas (franja costera) y medias (valles atlánticos), localizándolo en el $62 \%$ de las cavidades prospectadas (frente al $66 \%$ de $R$. ferrumequinum y el y $28 \%$ de $R$. hipposideros), y calificando su estado de conservación como favorable, aunque afirma que varias cavidades importantes para la especie se encuentran amenazadas. Coincide con Goiti \& Aihartza (2005) en señalar que su distribución se ciñe a altitudes bajas y medias en el ámbito cantábrico.
Nosotros lo hemos hallado en pequeños y grandes grupos en cavidades subterráneas de toda Cantabria, si bien con menor frecuencia que las otras dos especies del género. Su mayor gregarismo, que le lleva a concentrar su población en unos pocos refugios, puede ser responsable en parte de esa menor frecuencia en el territorio, pero el número total de ejemplares localizados resulta también menor. Son 44 registros propios obtenidos hasta el presente en 27 localidades que cubren un tercio de la superficie regional (la mitad si incluimos otras fuentes), en altitudes entre el nivel del mar y 962 m s.n.m. (Fig. 7).

De los refugios hallados, trece fueron cavidades subterráneas y cuatro construcciones, siendo en Cantabria el rinolofo más ligado a cavidades subterráneas. En un caso se trató de un ejemplar solitario; en otro una hembra con una cría; otros cuatro casos con grupos menores de 10 ejemplares; y diez grupos con más de 10 ejemplares, destacando 52, 101 y 114 ejemplares en 2 cuevas y un pajar, este último compartido con tres especies más hasta sumar 445 individuos. De las 15 capturas diez fueron machos, cuatro hembras y uno no sexado. De las hembras, tres mostraban signos de estar reproduciéndose.

Por orden de importancia, los hábitats más frecuentados donde fue capturado fueron robledales, hayedos, pastizales, prados con setos y eucaliptal. Lo hemos hallado menos frecuente en riberas que las otras dos especies del género.

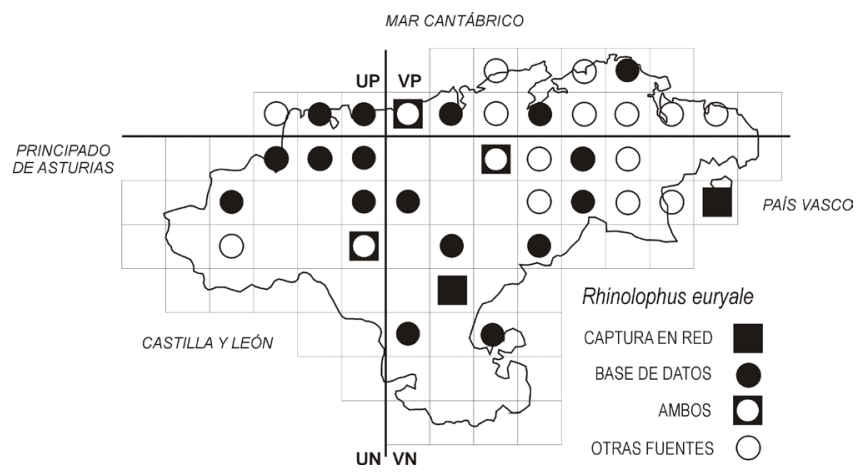

Fig. 7 - Distribución de Rhinolophus euryale en Cantabria según cuadrícula UTM de $100 \mathrm{~km}^{2}$. // Distribution of Rhinolophus euryale according to $100-\mathrm{km}^{2}$ UTM grid.

\section{Murciélago ratonero grande Myotis myotis Borkhausen, 1797}

Valverde (1953) lo cita para la cueva de La Castañera, y Menéndez (1973) estudia la colonia reproductora de la cueva del Calero, mixta con Miniopterus schreibersi. Aunque no la censa, refiriéndose a una disgregación en grupos en fase previa a los partos, deja entrever que se compone de varios cientos de individuos de $M$. myotis y cuatro veces más de Miniopterus cuando dice: “...encontrándose los quirópteros diseminados por toda la caverna, formando pequeñas colonias específicas en numerosos puntos de la cueva. Estas mini-agrupaciones constaban de unos 200 individuos para los Miniopterus y de unos 50 para los Myotis". En la actualidad la cueva es LIC, pero a pesar de ello sufre graves impactos, pues tiene un cierre perimetral destruido que no impide numerosas visitas incontroladas, y el río que la 
atraviesa está desecado por una captación de agua desde hace muchos años, habiéndose reducido enormemente la colonia mixta. Tupinier (1982) colecta ejemplares y restos óseos en varias cavidades de la región a comienzos de la década de 1970.

Años más tarde Meijide (1982) lo señala abundante en Cantabria, citando 33 refugios ocupados, de los cuales 25 son cavidades subterráneas y ocho edificios. Hemos revisado 12 de ellos veinticinco años después con el siguiente resultado: una reducción de las poblaciones que los ocupan en tres de ellos, causadas fundamentalmente por visitas incontroladas; seis son cuevas que han sido cerradas para proteger yacimientos arqueológicos y captaciones de agua, habiendo desaparecido las colonias; otras dos cuevas fueron completamente destruidas por canteras; y un edificio fue restaurado, inutilizándose como refugio.

Hemos reunido 30 registros obtenidos por análisis genético, identificación en mano y revisión de colonias conocidas, en 15 localidades repartidas por el $22 \%$ de la superficie regional, entre el nivel del mar y 978 m s.n.m. (Fig. 8). Otros 35 registros, en su mayor parte mediante observación y escucha simultánea, no pueden en rigor atribuirse a $M$. myotis sino al complejo $M$. myotis/blythii, si bien esta última especie no ha sido confirmada en Cantabria. M. blythii había sido únicamente citado por Meijide (1982) en cuatro cuevas, pero revisiones posteriores consideran errónea su identificación (F. González, com. pers.).

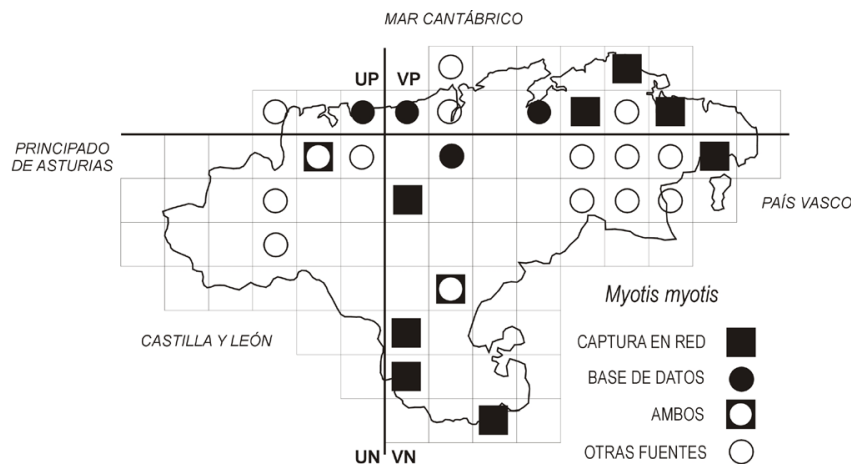

Fig. 8 - Distribución de Myotis myotis en Cantabria según cuadrícula UTM de $100 \mathrm{~km}^{2}$. // Distribution of Myotis myotis according to 100 $\mathrm{km}^{2}$ UTM grid.

Las dos colonias reproductoras de $M$. myotis ocupaban cuevas y reunían 62 y 184 individuos. En otras cavidades se observaron entre uno y tres ejemplares. De las 14 capturas, seis fueron en el acceso a refugios y el resto en lugares alejados de estos, resultando diez machos y cuatro hembras, mostrando una de ellas signos de reproducción.

Teniendo en cuenta las referencias antiguas citadas más arriba, la especie parece haber experimentado un declive, ya que no se observa en algunos refugios donde fue citada, o lo hace en menor número o menor frecuencia. El deterioro de las condiciones de las cavidades subterráneas es probablemente causa directa de ello. Pero también puede haber contribuido el deterioro de los ambientes de campiña atlántica (prados con setos) que constituyen su hábitat preferente de caza, ya que en las últimas décadas, los cambios en la gestión agropecuaria de estos ambientes ha propiciado una reducción muy notable en las poblaciones de especies presa en tales áreas.

\section{Murciélago ratonero forestal Myotis bechsteinii Kuhl, 1817}

Meijide (1982) lo consideraba extremadamente raro y desconocido en Cantabria, pero presente en base a restos óseos hallados en cuevas y analizados por Tupinier (1982): en concreto seis mandíbulas y un radio procedentes de tres cavidades subterráneas, cuya correcta identificación ha sido puesta en duda posteriormente (Catálogo Regional de Especies Amenazadas de Cantabria 2008). Ningún otro dato se ha tenido hasta los ejemplares analizados aquí: 13 individuos capturados con redes de niebla en cinco localidades correspondientes a cuatro cuadros UTM de 100 $\mathrm{km}^{2}$ (Fig. 9). Sin embargo, la dispersión de dichas capturas, lo común en la región de los ambientes donde se ha encontrado, así como la gran extensión de masas forestales maduras autóctonas, nos hace pensar en la posible existencia de una población relativamente abundante y con distribución amplia de esta especie en Cantabria.

Ocho ejemplares fueron hembras y cuatro machos (uno no sexado), todos ellos adultos. Cinco hembras en dos localidades mostraron signos de reproducción. Las capturas se realizaron en linderos de bosques maduros diversos con Quercus robur, Q. pyrenaica, Castanea sativa, Fraxinus excelsior, Fagus sylvatica, Alnus glutinosa, y otros, con la excepción de un macho capturado en un collado a $704 \mathrm{~m}$ de altitud, un paraje excepcionalmente abierto de pastizales y brezales, aunque cerca del lindero de una plantación de Pinus sylvestris. Las altitudes variaron entre 147 y 798 m s.n.m.

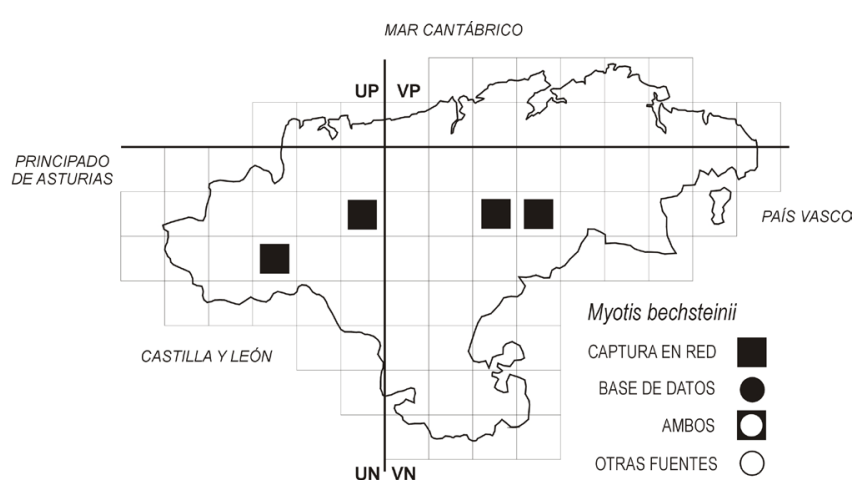

Fig. 9 - Distribución de Myotis bechsteinii en Cantabria según cuadrícula UTM de $100 \mathrm{~km}^{2}$. // Distribution of Myotis bechsteinii according to $100-\mathrm{km}^{2}$ UTM grid.

\section{Murciélago ribereño Myotis daubentoni Kuhl, 1817}

En tanto se aclare el estatus taxonómico de las diferentes formas del complejo Myotis daubentonii sujeto a estudio en la actualidad, consideramos aquí conjuntamente los ejemplares analizados en Cantabria como Myotis daubentonii s.l. Pueden consultarse a este respecto los trabajos de Bogdanowicz (1990) y Simoes et al. (2007), basados en caracteres físicos y genéticos respectivamente. 
A pesar de resultar abundante y bien distribuido según hemos comprobado, apenas se ha publicado nada sobre este taxón en la Comunidad autónoma. Meijide (1982) lo consideraba raro y escaso, localizado solo en el valle del río Asón, error debido a la casi nula prospección de quirópteros fisurícolas que entonces se realizaba. Como refugios para la especie cita las grietas de un puente, según observaciones de Tupinier y Menéndez (Tupinier, 1982), y unas cavidades subterráneas próximas. En la década de 1990, el equipo formado por González-Álvarez y Rodríguez-Muñoz (com. pers.), que trabajaron con detectores para el proyecto Atlas de Vertebrados de Cantabria, amplían su presencia a otras comarcas hasta cubrir un tercio de la superficie regional. Finalmente Toca (2003b) refiere el seguimiento de una colonia reproductora en la zona sur de la Región.

Por nuestra parte hemos obtenido 234 registros en 110 localidades ampliamente distribuidas en el territorio de estudio, entre el nivel del mar y 1306 m s.n.m. (Fig. 10); esta última cota en un collado de montaña. Fueron capturados 122 individuos, de los que se tomaron 29 biopsias como apoyo a la discriminación taxonómica de sus morfotipos. La desproporción entre sexos fue notable, con 94 machos frente a 20 hembras (ocho ejemplares no fueron sexados). Esto supone un $82 \%$ de machos. Las localidades con solo machos fueron 31 , con machos y hembras 11 , y con solo hembras, una (Fig. 11). En estudios publicados (Dietz et al. 2006, Lučan \& Hanák 2011), la desproporción fue menor, señalando como causas probables una segregación debida a variaciones en abundancia de recursos entre zonas, con los machos ocupando las áreas más pobres; y concentraciones temporales de ejemplares en estaciones de swarming. Diez de las hembras capturadas, procedentes de 4 localidades, mostraron indicios de estar reproduciéndose.

Relativo a morfotipos, predominaron los individuos con caracteres externos que se consideran propios de la subespecie nominal, con solo una pequeña proporción (inferior al 30\%) de aquellos asimilables al morfotipo nathalinae, que fue descrito como especie nueva en 1977 por Tupinier (1977) a partir de ejemplares de Cabezasrrubias (Ciudad Real), habiendo colectado por aquel tiempo especímenes que también asimiló a este morfotipo en Arredondo (Cantabria).

En agosto de 2007 realizamos una estimación de la actividad de esta especie en un tramo de $12,2 \mathrm{~km}$ del río Ebro en el municipio de Valderredible, mediante el recuento de individuos vistos a la luz de un foco y con ayuda de un detector heterodino. Dicho conteo se realizó en once tramos del río que sumaron $2,1 \mathrm{~km}$, con el resultado de 33 detecciones, lo que supone 15,7 detecciones por kilómetro de río.

La especie resulta extremadamente constante campeando sobre cuerpos de agua dulce, desde pequeños arroyos en zonas forestales, hasta orillas de embalses. No se limita a seguir los cauces, sino que visita puntos de agua dispersos y alejados entre sí. Parte de su actividad de caza puede realizarse en ambientes forestales y linderos. Esta especie también fue detectada en las rías cantábricas, aunque no podemos precisar aún si caza en los ambientes salinos de las zonas intermareales.

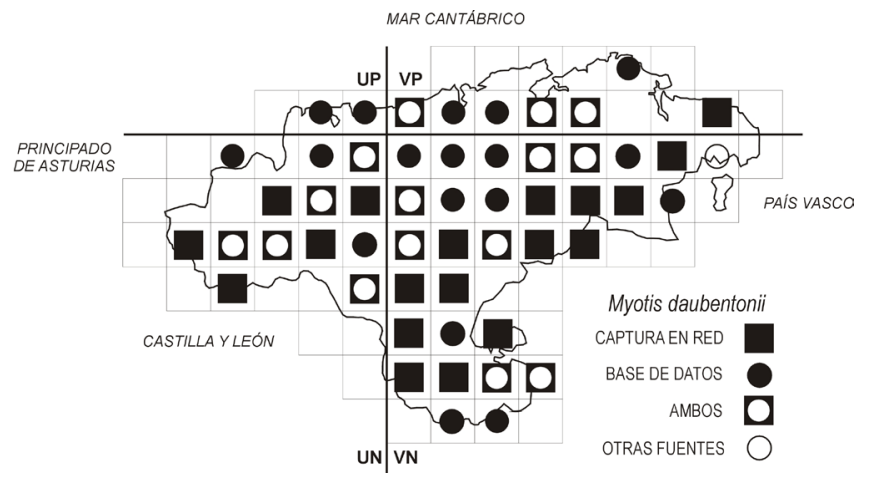

Fig. 10 - Distribución de Myotis daubentonii en Cantabria según cuadrícula UTM de $100 \mathrm{~km}$. // Distribution of Myotis daubentonii according to $100-\mathrm{km}^{2}$ UTM grid.

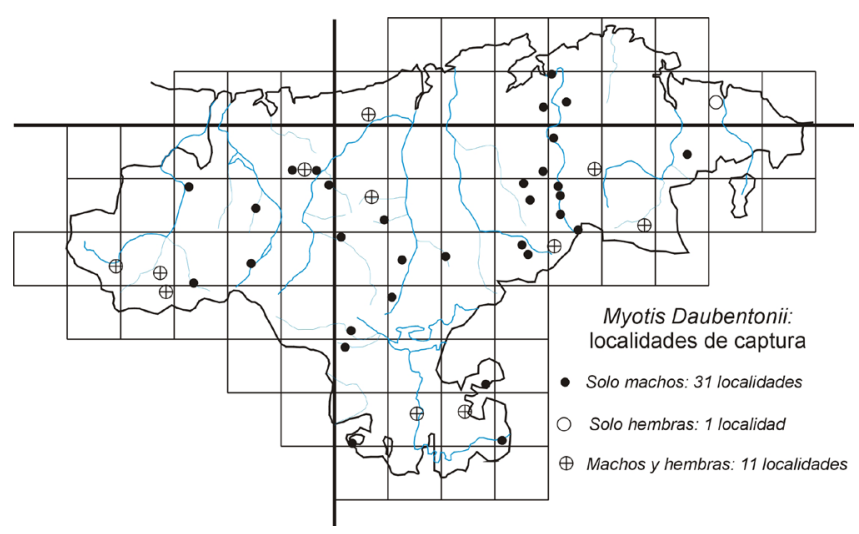

Fig. 11 - Distribución de las localidades donde se capturaron solo machos (31 localidades, 94 ejemplares); machos y hembras conjuntamente (11 localidades, 19 ejemplares); solo hembras (1 localidad, 1 ejemplar) de M. daubentonii en Cantabria (datos propios). // Distribution of the localities where only males were captured (40 localities, 94 specimens); males and females together (11 localities, 19 individuals); only females (1 locality, 1 copy) of $M$. daubentonii in Cantabria (own data).

\section{Murciélago ratonero gris ibérico Myotis escalerai Cabrera 1904}

Aportamos aquí las primeras determinaciones específicas para este taxón en Cantabria, a partir del análisis genético de 5 ejemplares, 3 machos, 1 hembra y un ejemplar no sexado, capturados en 2016 y 2017 en cinco localidades del sur, en los valles del Alto Ebro y el Camesa (este último de la cuenca del Duero) en altitudes entre 566 y 950 m s.n.m. (Fig. 12), lo que supone un área muy restringida. El hábitat dominante en todos los casos es robledal de Quercus pyrenaica, y campiña con setos que siguen arroyos y delimitan parcelas agrícolas.

A diferencia de su especie gemela Myotis cf nattereri, que parece ser común y ampliamente distribuida por la Comunidad Autónoma de Cantabria en ambientes pertenecientes a los pisos Colino y Montano de la Región Eurosiberiana, M. escalerai, a tenor del resultado obtenido hasta el momento, parece acantonado en la zona de transición al Supramediterráneo (Rivas-Martínez 1983), donde es sintópica con la anterior especie.

Hemos encontrado gran dificultad al separar esta especie de Myotis cf. nattereri por los caracteres morfológicos 
externos habitualmente aducidos: inserción patagiotobillo y filas pilosas del uropatagio (Salicini et al. 2012), a diferencia de las otras dos especies crípticas M. alcathoe / M. mystacinus que no plantearon problemas.

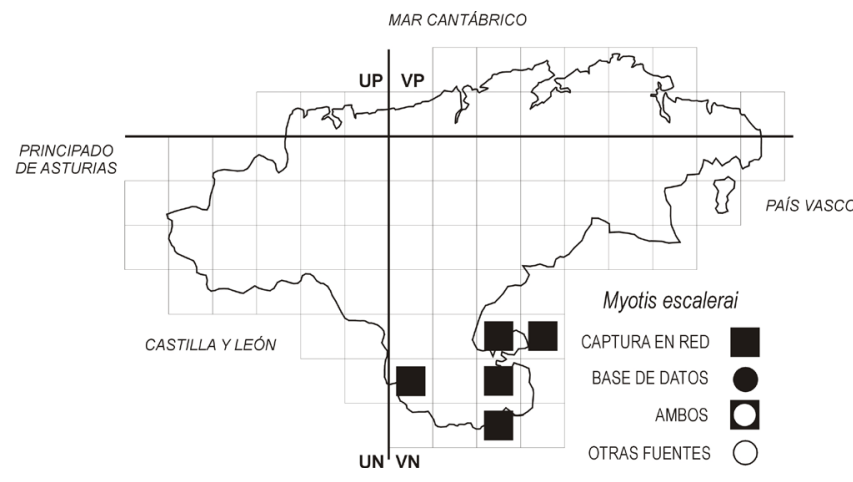

Fig. 12 - Distribución de Myotis escalerai en Cantabria según cuadrícula UTM de $100 \mathrm{~km}^{2}$. // Distribution of Myotis escalerai according to $100-\mathrm{km}^{2}$ UTM grid.

\section{Murciélago ratonero gris itálico Myotis cf. nattereri Kuhl, 1817}

Para la caracterización específica de este taxón y primeros registros en la Península Ibérica ver Ibáñez et al. (2006), Salicini et al. (2011) y Aguirre-Mendi \& Ibáñez (2012). Hay muy pocos registros antiguos atribuidos a Myotis nattereri s. I. en Cantabria, tan solo las citas de Tupinier (1982) y Meijide (1982) correspondientes a huesos y un ejemplar, colectados en dos cavidades subterráneas y un edificio, y una observación nuestra de un ejemplar del complejo nattereri en otra cavidad subterránea. Con la separación actual en dos especies presentes en la Península lbérica del antiguo $M$. nattereri, no es posible asignar tales registros a una especie concreta. Por esta razón, consideramos aquí únicamente los 80 ejemplares con análisis genético, obtenidos por nosotros entre 2015 y 2017, capturados en 45 localidades dispersas por toda la región, en altitudes entre el nivel del mar y 1.642 m s.n.m. (Fig. 13). De los ejemplares sexados, 39 fueron hembras y 32 machos. Entre las hembras, al menos 19 mostraron signos de estar reproduciéndose.

Los hábitat de captura fueron en su mayor parte forestales, variando desde el interior de bosques maduros con densa cobertura, hasta campiña con setos arbolados y con regueros de arbolado joven sobre los regatos, pasando por todo tipo de desarrollos y estructuras del arbolado, y

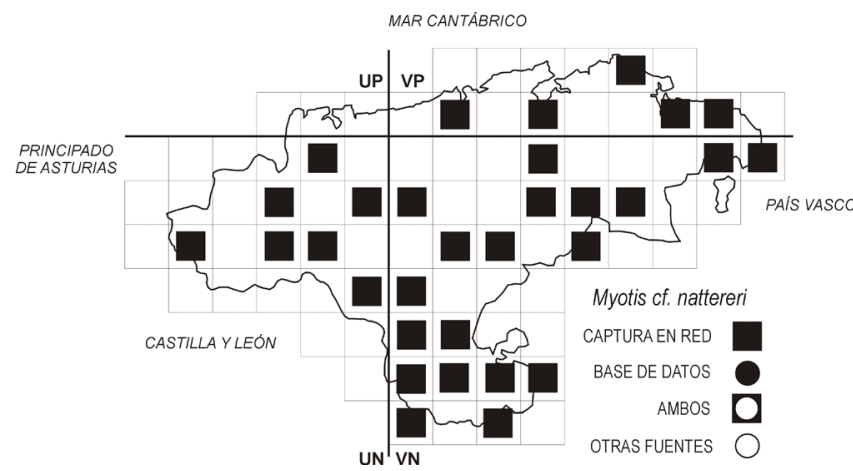

Fig. 13 - Distribución de Myotis cf. nattereri en Cantabria según cuadrícula UTM de $100 \mathrm{~km}^{2}$. // Distribution of Myotis cf. nattereri according to $100-\mathrm{km}^{2}$ UTM grid. desde lo eminentemente atlántico hasta lo continental y lo supra-mediterráneo, incluida una plantación madura de Pinus radiata. También en medios de sustitución abiertos como brezales, escobales y landa costera.

Lo consideramos extendido y común en Cantabria, en los hábitats mencionados, ocupando toda la zona correspondiente a la Región Eurosiberiana, y al menos los límites con el Supramediterráneo, donde habita en sintopía con M. escalerai.

\section{Murciélago ratonero pardo Myotis emarginatus Geoffroy, 1806}

Los primeros datos para la especie en Cantabria los ofrece Tupinier (1982) al capturar una hembra con su cría en Arredondo en 1964, casi coincidente con la primera cita en España por parte de Balcells (1964). Posteriormente, aquel autor analiza restos de cuatro ejemplares capturados en algunas de las localidades dadas por Meijide (1982), quien considera a la especie rara y escasa en Cantabria, citando tan solo seis refugios ocupados entre las decenas analizados por él, de los que cinco son cavidades subterráneas y el otro un edificio, con lo que su distribución se dibujaba entonces muy restringida, ya que cuatro de dichos refugios se situaban próximos entre sí en la zona oriental, y los otros dos igualmente muy próximos entre sí en la central.

González (2016) obtiene resultados semejantes a partir del 2000, quien lo encontró en el $8 \%$ de las cavidades subterráneas prospectadas. En nuestra opinión subestimó la presencia de la especie en la región al no considerar refugios en construcciones, si bien es mucho lo que aún falta por conocerse sobre este taxón en Cantabria. En las mismas fechas F. González-Álvarez (com. pers.) menciona una colonia con unos cien ejemplares en un edificio abandonado de la zona occidental, que posteriormente fue restaurado excluyendo a la colonia.

Por nuestra parte, a pesar del elevado número de refugios revisado, tanto cavidades subterráneas como edificios, y del cuantioso esfuerzo de muestreo con redes, solo hemos obtenido 29 registros de la especie en 24 localidades dispersas por un tercio del territorio, lo que nos hace pensar, coincidiendo con Meijide (1982), que $M$. emarginatus pudiera resultar poco abundante en Cantabria, y repartido en un pequeño número de colonias (Fig. 14). Si bien, por otra parte, su acusado gregarismo, y su querencia por ocupar refugios en habitáculos de construcciones bien aislados del exterior, hace que sus colonias sean a menudo inaccesibles al investigador, pudiendo pasar desapercibidas, lo que llevaría a una subestimación de su real abundancia.

De los refugios analizados siete eran construcciones y tres cavidades subterráneas. En tres ocasiones se trató de ejemplares solitarios ocupando un refugio nocturno; y en seis casos fueron refugios con grupos reproductores, con un número de ejemplares de 220, 113, 102, 59, 23 y 6 . Las observaciones se produjeron desde el nivel del mar hasta 1085 m s.n.m.

Relativo a las capturas en red, en 2016 y 2017 obtuvimos 18 ejemplares de los que ocho eran machos y diez hembras, siete de ellas con signos de estar reproduciéndose. Los 
hábitats fueron diversos: campiña atlántica $28 \%$, encinar $22 \%$, robledal de $Q$. robur y riberas $13 \%$ cada uno, arbolado mixto $9 \%$, pueblo $6 \%$, y roquedo, eucaliptal y hayedo $3 \%$ cada uno.

Especie termófila en Cantabria, estimamos que existe una semejanza de esta especie con $R$. euryale en cuanto a selección de hábitat, gregarismo y dispersión de sus colonias en el territorio, si bien con mayor tendencia a ocupar edificios durante la reproducción que aquella especie.

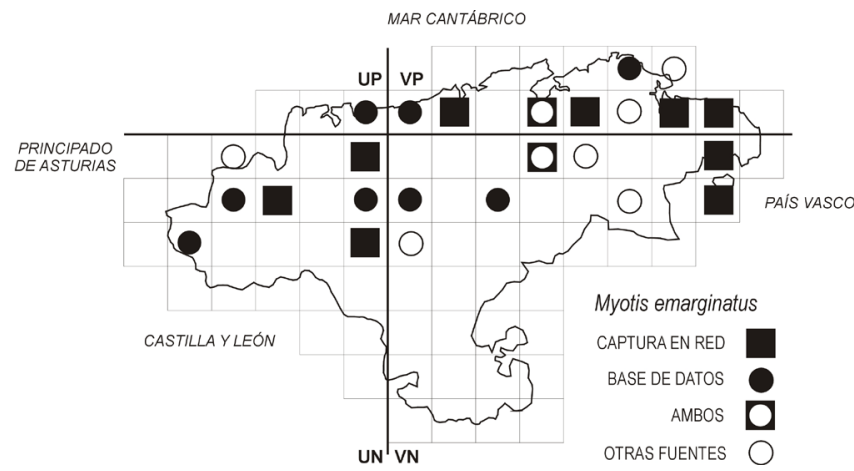

Fig. 14 - Distribución de Myotis emarginatus en Cantabria según cuadrícula UTM de $100 \mathrm{~km}^{2}$. // Distribution of Myotis emarginatus according to $100-\mathrm{km}^{2}$ UTM grid.

\section{Murciélago bigotudo enano Myotis alcathoe Helversen \& Heller, 2001}

Trabajando con detectores en años pasados, se sospechó que pertenecían a esta especie ciertos ejemplares que patrullaban casi rasantes los arroyos en el interior de bosques bajo un túnel arbolado o arbustivo, lo que luego hemos confirmado como cierto mediante la captura, entre 2015 y 2017 de 99 ejemplares, 41 identificados por análisis genético, y los restantes morfológico. Todos los individuos con análisis genético habían sido previamente identificados correctamente como $M$. alcathoe en base a caracteres externos, por lo que, a partir de determinado momento, se consideró innecesario realizar dicha analítica; no obstante se conservan muestras tisulares de todos ellos. Consideramos válidas las descripciones dadas por Dietz \& Helversen (2004) para separar esta especie de $M$. mystacinus en la zona de estudio, si bien recurrimos a análisis genéticos en los pocos casos en que se capturaron ejemplares con caracteres intermedios (siempre jóvenes).

Las capturas se realizaron en 50 localidades bien repartidas por una amplia zona, en todas las cuencas (atlántica, del Ebro y del Duero) en altitudes entre 160 y 1.100 m s.n.m., lo que constituye la primera información sobre este taxón en Cantabria (Fig. 15).

De ellos, 44 fueron machos y 41 hembras (para 15 ejemplares no consta el dato). De las últimas, en 26 se apreciaron signos de estar reproduciéndose en al menos 18 localidades. Todas las capturas se hicieron en arroyos o en sus proximidades, atravesando bosques y en menor medida campiña arbolada. Los bosques fueron, a partes iguales, robledales de Quercus pyrenaica y $Q$. robur, y en menor medida, campiña arbolada y masas de Fagus sylvatica y $Q$. petraea.
La planificación de las capturas, dirigida a especies forestales crípticas, ha tenido reflejo en los buenos resultados obtenidos para esta especie, debido sin duda también a su abundancia y amplia distribución, de la que sin embargo no se contaba con información previa al no haberse empleado una metodología adecuada. No ha ocurrido así hasta el momento con la especie críptica $M$. mystacinus, de la que se han obtenido escasos registros.

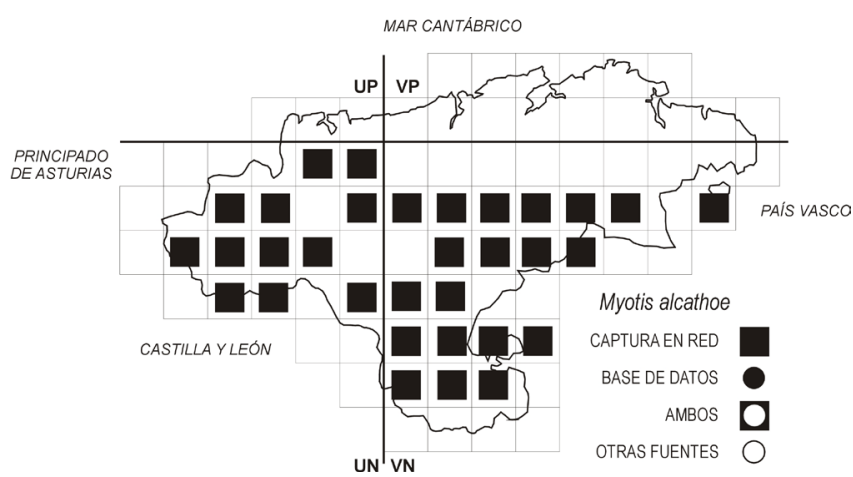

Fig. 15 - Distribución de Myotis alcathoe en Cantabria según cuadrícula UTM de $100 \mathrm{~km}^{2}$. // Distribution of Myotis alcathoe according to $100-\mathrm{km}^{2}$ UTM grid.

\section{Murciélago bigotudo Myotis mystacinus Kuhl, 1817}

Fue citado por Meijide (1982), al igual que M. bechsteinii, como raro y poco conocido en la región. Se refería en ambos casos a restos óseos analizados por Tupinier (1982). Aportaba además para $M$. mystacinus s. I. la observación de un ejemplar en un desván entre un grupo multiespecífico, sin datos biométricos que apoyaran la validez de la identificación, que consideramos muy dudosa. Por otra parte, los registros atribuidos a $M$. mystacinus anteriores a su separación de M. alcathoe, que no impliquen conservación de material genético para su análisis, no pueden ser adjudicados a ninguna de ambas especies.

No hay ninguna otra observación válida hasta nuestras capturas, que suponen por lo tanto las primeras identificaciones fehacientes de la especie en Cantabria. Son siete ejemplares procedentes de cinco localidades del sur de la región, obtenidos mediante captura en red e identificados mediante análisis genético. Se trató en el primer caso de un macho y una hembra de la misma localidad y noche, estando la hembra lactando, lo que confirma su reproducción en Cantabria. A los que siguieron dos machos de otras localidades, y tres hembras de otras dos, una de ellas lactante. Los hábitat de las capturas fueron tres forestales y dos abiertos: robledal de Quercus pyrenaica, robledal de Q. faginea, hayedo, campiña con setos y campiña abierta, con presencia de ambientes de ribera. Las cinco localidades se hallan situadas próximas entre sí, en zonas elevadas de la vertiente sur de la Cordillera cantábrica, situadas entre 895 y 995 m s.n.m., en los valles del alto Ebro y el Camesa, este último de la cuenca del Duero, dentro de la Provincia Orocantábrica de la Región Eurosiberiana, lo que supone un área muy restringida (Fig. 16) 
Creemos oportuno insistir en la alta frecuencia de captura y amplia distribución que está mostrando $M$. alcathoe en Cantabria, en contraste con la escasez y dificultad de localización hasta el momento de $M$. mystacinus.

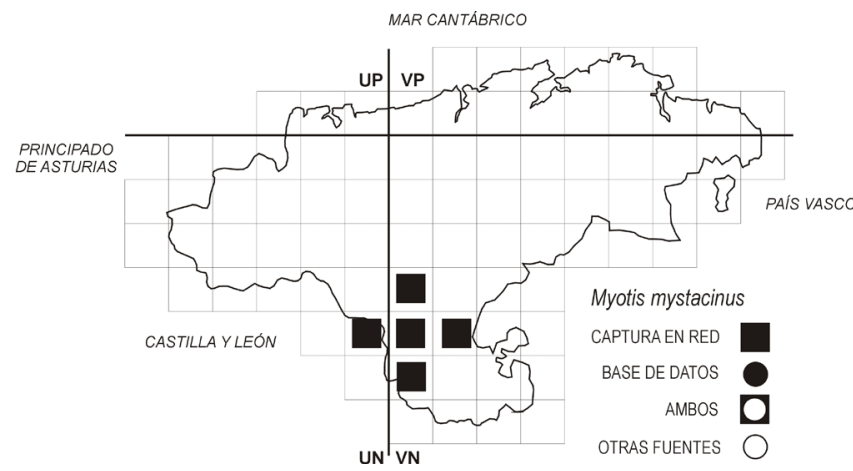

Fig. 16 - Distribución de Myotis mystacinus en Cantabria según cuadrícula UTM de $100 \mathrm{~km}^{2}$. // Distribution of Myotis mystacinus according to $100-\mathrm{km}^{2}$ UTM grid.

\section{Murciélago enano Pipistrellus pipistrellus Schreber, 1774}

A pesar de resultar muy abundante y ampliamente distribuido en la región, apenas se ha publicado nada sobre este taxón en la Comunidad Autónoma de Cantabria, si exceptuamos Toca (2003b) y Fombellida (2012b).

Nuestra base de datos cuenta con 1.110 registros de la especie, la mayor parte detecciones por ultrasonidos, a los que hay que sumar 660 capturas en red que suponen el $37 \%$ del total, realizadas en 112 localidades (el 53\% del total de puntos muestreados) (Fig. 17). De 363 ejemplares sexados, 182 fueron hembras y 181 machos. Ejemplares en fase reproductiva se hallaron ampliamente distribuidos. Ha sido la especie más frecuente y abundante en nuestros muestreos con detectores en todas las comarcas y hábitats, excepto quizá algunas localidades más cálidas, urbanas o de cierta aridez de la franja costera, donde puede ser puntualmente superado por Pipistrellus kuhlii.

Resulta asimismo fácil localizar colonias recurriendo a las encuestas, ya que son muchas las personas consultadas que conocen o han observado alguna vez un grupo ocupando fisuras de edificios. Lo hemos detectado en todos los ambientes, desde el nivel del mar, hasta 2.000 metros en áreas de pastizal y brezal de montaña.

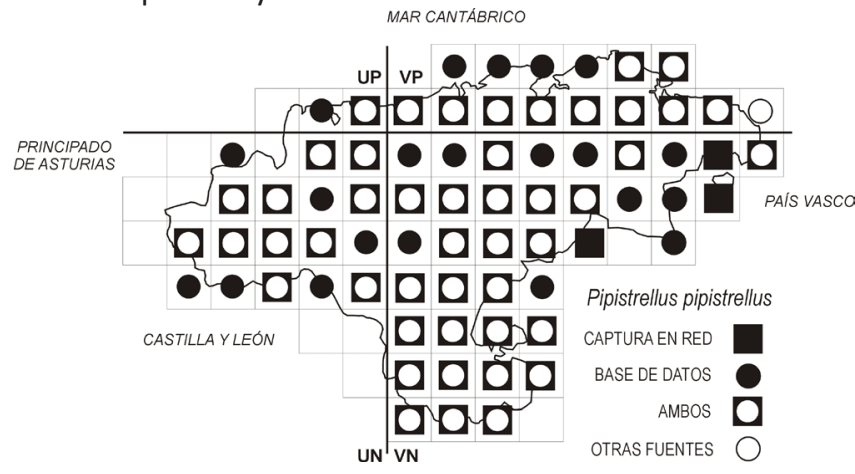

Fig. 17 - Distribución de Pipistrellus pipistrellus en Cantabria según cuadrícula UTM de $100 \mathrm{~km}^{2}$. Distribution of Pipistrellus pipistrellus according to $100-\mathrm{km}^{2}$ UTM grid.
En un estudio de la ocurrencia de quirópteros en la franja costera de Cantabria (Fombellida 2012b), fue la especie más común con un índice de abundancia de 3,36 contactos/km. De hecho, lo hemos hallado en 54 cuadros UTM de 100 km², abarcando la práctica totalidad de la superficie regional).

\section{Murciélago de Cabrera \\ Pipistrellus pygmaeus Leach, 1825}

Teníamos su presencia como probable en base a cuatro escuchas con detector en tres localidades, lo que ha sido confirmado finalmente mediante análisis de sonogramas en seis localidades, todas ellas riberas fluviales. Se aprecia que se trata de una especie poco frecuente en comparación con el omnipresente $P$. pipistrellus (Fig. 18).

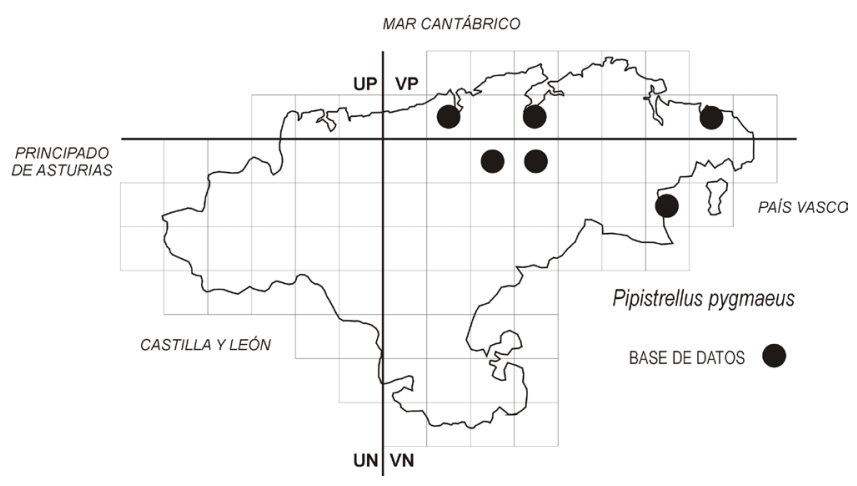

Fig. 18 - Distribución de Pipistrellus pygmaeus en Cantabria según cuadrícula UTM de $100 \mathrm{~km}^{2}$. // Distribution of Pipistrellus pygmaeus according to $100-\mathrm{km}^{2}$ UTM grid.

\section{Murciélago de borde claro Pipistrellus kuhlii Kuhl, 1819}

A pesar de resultar abundante y distribuido en Cantabria, no comenzó a localizarse hasta el empleo de detectores en las décadas de 1990 y 2000 por González-Álvarez y Rodríguez-Muñóz (Toca 2003a), en los trabajos para el Atlas de Vertebrados de Cantabria, aunque este autor se contradice al afirmar más adelante: "Hasta el momento no se han citado murciélagos de las especie Pipistrellus kuhlii (en Cantabria) pero su presencia en zona asturiana, castellano-leonesa y vasca hace prever que en Cantabria también se asiente".

Por nuestra parte, comenzamos a localizarlo mediante detectores desde 2003 (Fombellida 2012b). Disponemos de 363 registros en nuestra base de datos, en su mayor parte detección por ultrasonidos, y 16 capturas, con el mismo número de hembras que machos, y solo un juvenil entre ellos (Fig. 19). De las hembras, cuatro mostraban signos de estar reproduciéndose.

Lo hemos hallado en un área que supone el $40 \%$ de la superficie regional, desde el nivel del mar hasta 918 m s.n.m., si bien esta última cota, correspondiente a un collado de montaña, parece excepcional, ya que ocupa preferentemente zonas bajas de la franja costera y los valles cantábricos, con solo un $15 \%$ de localizaciones por encima de los 100 m s.n.m. 
Especie termófila en la región, muestra una evidente dependencia de factores climáticos y de los ambientes humanizados, ocupando la franja costera y los núcleos de población situados en las vegas de los principales valles, de cotas bajas y temperatura media anual más elevada (Fig. 20). En zonas del interior se detectó únicamente en alumbrado urbano, faltando en ambientes naturales y cotas más elevadas, siendo una de las pocas especies de quirópteros que presenta en Cantabria una distribución restringida claramente ligada a factores biogeográficos.

Los 654 registros con información sobre hábitat se reparten así: riberas (20\%), campiña costera (18\%), poblaciones (18\%), y arbolado mixto con claros (15\%). Otros ambientes de dichas comarcas, donde, de manera puntual, puede resultar la especie más frecuente superando al omnipresente $P$. pipistrellus, son los de tendencia árida y más temperada tales como zonas urbanizadas, parques y jardines, dunas, pinares de repoblación y canteras. Vive en sintopía con P. pipistrellus, cazando juntos sobre cuerpos de agua y arbolado ribereño. Con mucha frecuencia hemos observado como $P$. kuhlii expulsa a $P$. pipistrellus en jardines urbanos y el confinado ámbito de las farolas.

En un estudio que analiza la frecuencia de quirópteros en la franja costera de Cantabria (Fombellida 2012b), fue la segunda especie por detrás de $P$. pipistrellus, con un índice de frecuencia de 2,58 contactos $/ \mathrm{km}$, solo un cuarto más escaso que dicha especie.

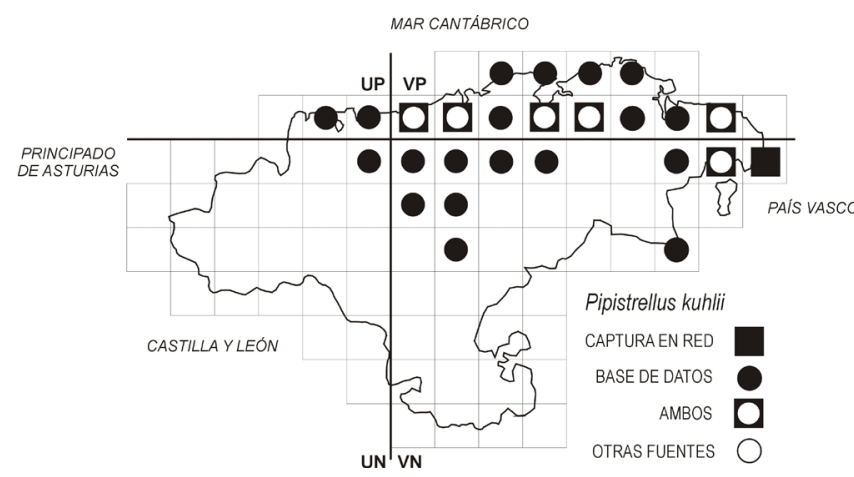

Fig. 19 - Distribución de Pipistrellus kuhlii en Cantabria según cuadrícula UTM de $100 \mathrm{~km}^{2}$. // Distribution of Pipistrellus kuhlii according to $100-\mathrm{km}^{2}$ UTM grid.

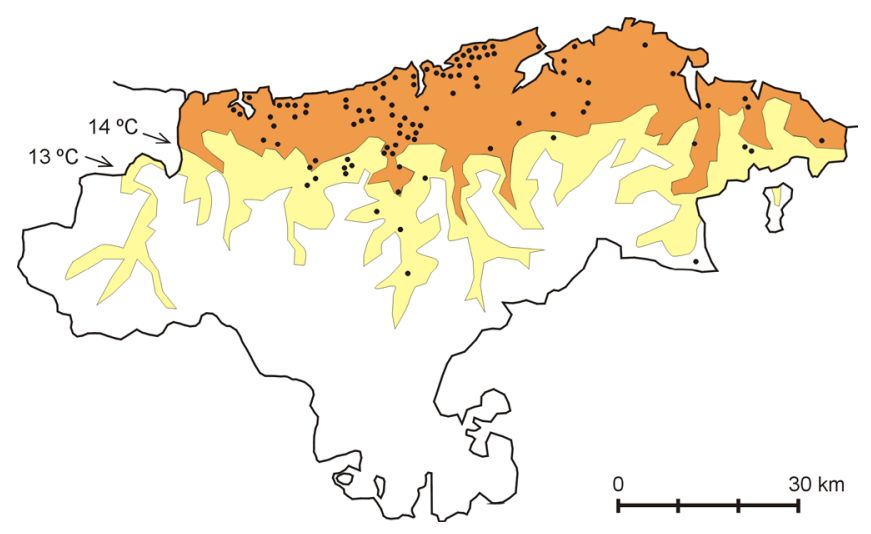

Fig. 20 - Distribución de nuestras observaciones de P. kuhlii en Cantabria en relación a las isotermas de 13 y 14 ㅇ C de temperatura media anual. // Distribution of our observations of $P$. kuhlii in Cantabria together with isotherms of 13 and $14 \stackrel{\circ}{ } \mathrm{C}$ of average annual temperature.

\section{Murciélago enano de bosque Pipistrellus nathusii Keyserling \& Blasius, 1839}

Su presencia en Cantabria se constató en base a un espécimen capturado en Muriedas en 1913 que se determinó como perteneciente a esta especie (Benzal \& De Paz 1991). Además Rodríguez-Muñóz et al. (1993-94) refieren la detección acústica de la especie en Guriezo en junio de 1991. De todas formas, recientemente hemos confirmado a la especie en base a sonogramas de sus cantos sociales (Barataud 1995), entre los meses de febrero y julio, en seis localidades correspondientes a riberas fluviales y el Embalse del Ebro, previendo en breve la captura de ejemplares para análisis en mano, así como la confirmación de su presencia a lo largo de todo el año (Fig. 21).

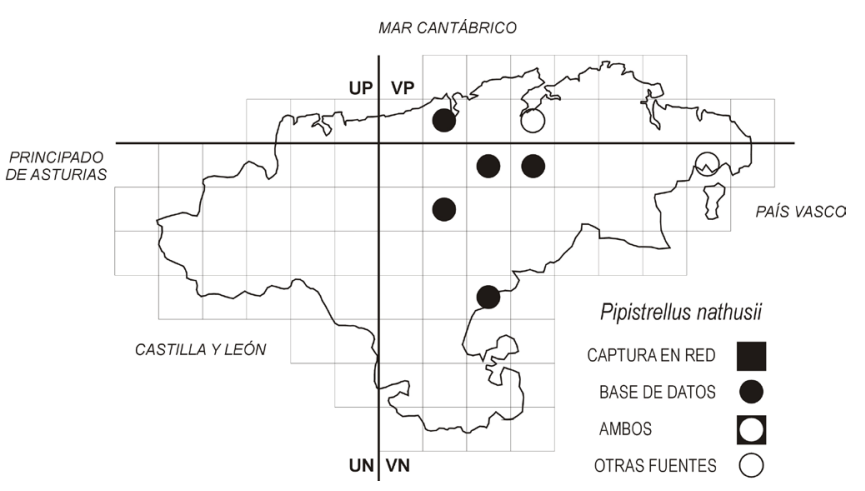

Fig. 21 - Distribución de Pipistrellus nathusii en Cantabria según cuadrícula UTM de $100 \mathrm{~km}^{2}$. // Distribution of Pipistrellus nathusii according to $100-\mathrm{km}^{2}$ UTM grid.

\section{Murciélago montañero Hypsugo savii Bonaparte, 1837}

Toca (2003a) refiere la primera detección de la especie por Rodríguez-Muñóz et al. (1993-94) en el Atlas de Vertebrados de Cantabria. No obstante, nada se ha publicado sobre este taxón en Cantabria hasta el presente, a excepción de Fombellida (2012b), quien reporta su observación directa y detección por ultrasonidos desde 2003 (Fombellida et al. 2004, Fombellida 2012a). Además de lo anterior, desde 2015 hemos realizado capturas en red, principalmente en bebederos cercanos a los roquedos donde se refugian, y nuevas detecciones por ultrasonidos, hasta reunir 94 registros en 40 localidades (Fig. 22). De 24 ejemplares sexados la mitad fueron machos y la mitad hembras. En cuatro localidades las hembras presentaron signos de reproducción.

Las observaciones se distribuyen por una extensión equivalente a un tercio de la superficie, si bien consideramos que la especie ocupa toda la región, lo cual será verificable en la medida en que se hagan muestreos específicos en el futuro. Las altitudes han variado desde el nivel del mar, donde habitan acantilados costeros, hasta 1.095 m s.n.m.

Disponemos de 121 datos referentes a uso del hábitat: menos del $20 \%$ de los registros se produjeron en las inmediaciones de hábitats arbolados, mientras que ambientes abiertos como roquedos, pastizales y brezales sumaron un $15 \%$ cada uno y el $50 \%$ en conjunto. 
Nuestros datos sugieren cierta dependencia de zonas con los roquedos de mayor desarrollo, localizándose ejemplares solitarios o en grupo cazando en dichos ambientes. Igualmente frecuenta pastizales y brezales en cotas elevadas, y se halla de forma dispersa en cotas bajas, cerca de pequeños roquedos, acantilados marinos y poblaciones. Consideramos bastante incompleto el conocimiento actual para H. savii en Cantabria.

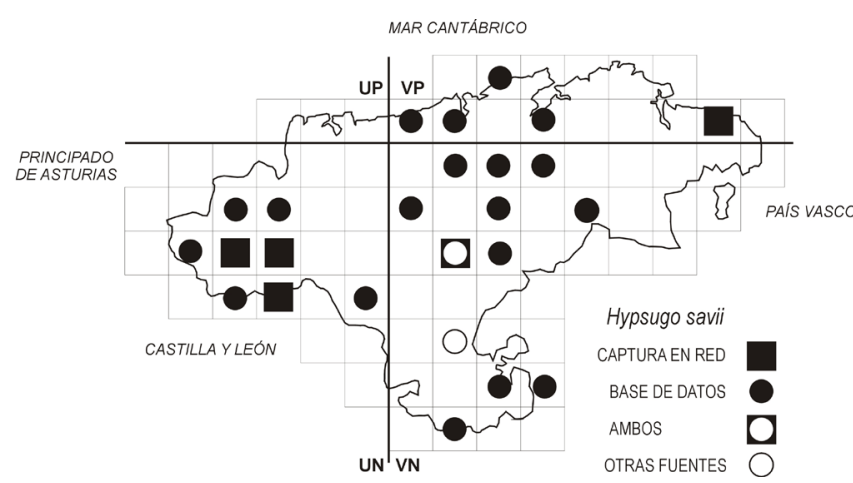

Fig. 22 - Distribución de Hypsugo savii en Cantabria según cuadrícula UTM de $100 \mathrm{~km}^{2}$. // Distribution of Hypsugo savii according to 100$\mathrm{km}^{2}$ UTM grid.

\section{Murciélago hortelano Eptesicus serotinus Schreber, 1774}

A pesar de resultar abundante y ampliamente distribuido en Cantabria, solo fue citado puntualmente por Meijide (1982) quien lo consideraba "frecuente pero poco conocido" en base al hallazgo de unos pocos ejemplares dispersos en sus refugios. Comenzó a localizarse de forma generalizada con el empleo de detectores de ultrasonidos en las décadas de los noventa y dos mil. Sin embargo, nada se publicó hasta el presente a excepción de Fombellida (2012b).

Actualmente tenemos 212 registros para esta especie de 126 localidades (Fig. 23), de los que 21 son ejemplares analizados en mano: 14 machos, cinco hembras y dos no sexados, todos ellos adultos excepto un juvenil. Dos de las hembras mostraban signos de reproducción.

Lo hemos hallado hasta el momento en un área equivalente a dos tercios del territorio, aunque lo más probable es que ocupe su totalidad, observándose en hábitat diversos, tanto naturales como humanizados, mostrando ser tan generalista como $P$. pipistrellus. Se encuentra desde nivel del mar hasta 1.306 m s.n.m., si bien la mayoría de las observaciones se produjeron entre 50 y 800 m s.n.m.

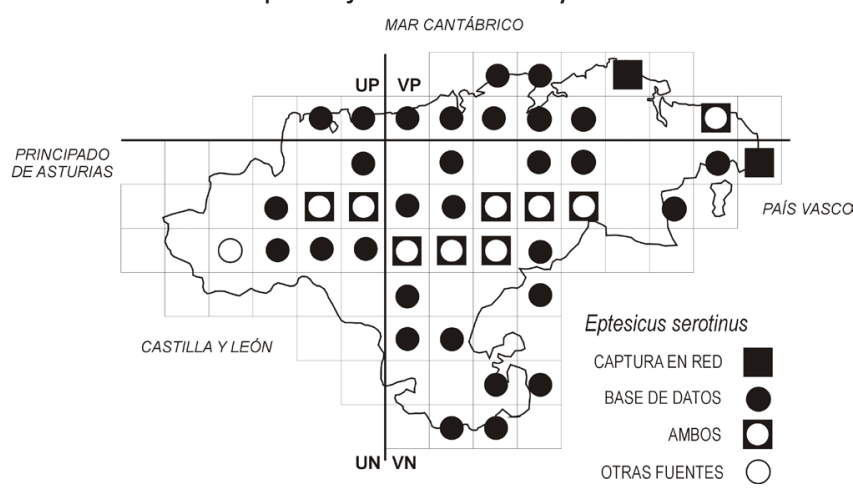

Fig. 23 - Distribución de Eptesicus serotinus en Cantabria según cuadrícula UTM de $100 \mathrm{~km}^{2}$. // Distribution of Eptesicus serotinus according to $100-\mathrm{km}^{2}$ UTM grid.
Disponemos de 431 datos referentes a uso del hábitat, el cual resulta muy diverso. Predomina la campiña con setos, las poblaciones, brezales y arbolado mixto. Caza con frecuencia a lo largo de las vegas de los ríos, pero también en laderas de monte cubiertas de brezales, pasto y helechal. Como refugios se han identificado fisuras y huecos en construcciones, roquedos y árboles.

Su frecuencia en la franja costera regional (Fombellida 2012b), fue de 0,19 contactos por kilómetro recorrido, frente al 6,75 del total de murciélagos. Fue la tercera especie en frecuencia, aunque muy detrás de $P$. pipistrellus y $P$. kuhlii.

\section{Nóctulo pequeño \\ Nyctalus leisleri Kuhl, 1819}

Es otra de las especies cuyos primeros testimonios en Cantabria proceden del uso de detectores para el Atlas de Vertebrados de Cantabria (Rodríguez-Muñóz et al. 1993-94). Diversos documentos inéditos lo recogen después (Fombellida et al. 2004, Saiz \& Fombellida 2006), con primeros datos publicados por Fombellida (2012b). Posteriormente lo hemos confirmado como especie común en la región mediante captura en redes de niebla, reuniendo 279 registros en 60 localidades, de los que 204 corresponden a capturas en 17 localidades (Fig. 24).

Lo hemos detectado en un área equivalente a la mitad del territorio, estimando que cubra un área mayor. Es abundante en el valle de Liébana (río Deva), y frecuente en las áreas montañosas de las vertientes norte y sur de la Cordillera cantábrica. Escasea hasta desaparecer en enclaves costeros, con menos arbolado maduro y ambientes más térmicos.

Hemos reunido 289 datos relativos al hábitat: el 44\% son arbolados, destacando robledales de Quercus robur y $Q$. pyrenaica, así como arbolado caducifolio mixto y pinares de repoblación. Los ambientes abiertos son frecuentados durante la caza, destacando la campiña de zonas montanas, y las zonas de pasto de ganado en régimen extensivo caracterizadas por la existencia de pastizales, brezales y helechales.

Localizado desde el nivel del mar hasta 1.605 m s.n.m., consideramos probable que algunos contactos mediante detector obtenidos en cotas altas de la Cordillera cantábrica hasta 2.200 m s.n.m., puedan corresponder a esta especie.

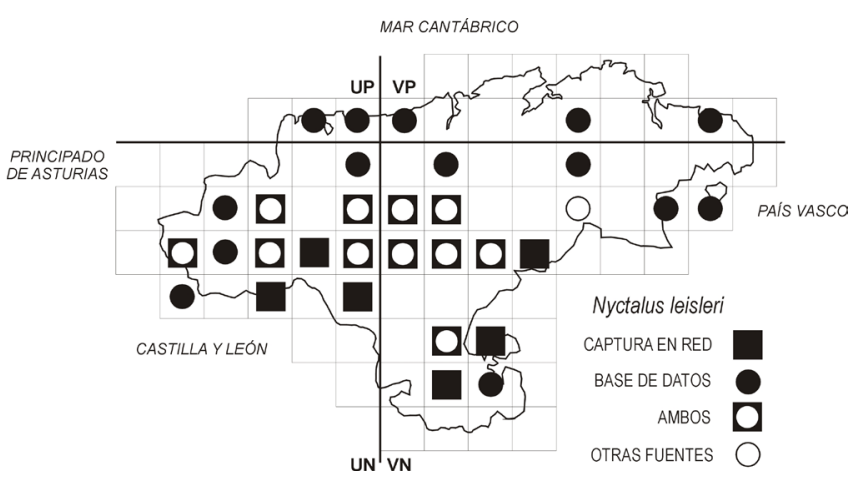

Fig. 24 - Distribución de Nyctalus leisleri en Cantabria según cuadrícula UTM de $100 \mathrm{~km}^{2}$. // Distribution of Nyctalus leisleri according to $100-\mathrm{km}^{2}$ UTM grid. 
De 173 ejemplares sexados, 164 fueron machos y solo nueve hembras. Estas se capturaron entre el 15 de agosto y el 4 de septiembre, mientras que los machos desde el 23 de mayo al 24 de septiembre. Sin embargo, ejemplares localizados mediante detectores y observación directa fueron registrados desde marzo hasta octubre. De 136 ejemplares, solo uno resultó juvenil.

\section{Nóctulo grande Nyctalus lasiopterus Schreber, 1780}

Nada se ha publicado sobre esta especie en Cantabria hasta la fecha. Nuestros primeros registros a partir de 2003 corresponden a escuchas mediante detector de ultrasonidos y observación directa en el crepúsculo, confirmando posteriormente su presencia mediante captura en redes de niebla. Son en total 38 registros los reunidos por nosotros de 20 localidades (Fig. 25), de los que ocho son ejemplares examinados en mano procedentes de tres puntos. De ellos, cinco son hembras con indicios de reproducción, capturadas en un mismo punto y noche, y los tres restantes machos de dos localidades distintas.

Aparte de las capturas, la separación de $N$. lasiopterus de $N$. noctula en los registros aquí incluidos se basa en los siguientes criterios: observaciones de ejemplares cazando en los crepúsculos con escuchas de pulsos irregulares a 15-16 kHz en diferentes épocas y años, en unos mismos parajes de montes forestados y abruptos. De todas formas, mantenemos dichos datos como probables. A tenor de lo observado, N. lasiopterus parece tener poblaciones estables en los bosques autóctonos caducifolios de los valles de Liébana (valle del río Deva), valles del nansa y el Saja, y el Alto Ebro, zonas que cubren la quinta parte del territorio regional, en altitudes entre 220 y 1.430 m s.n.m., la mayor parte entre 300 y 700 m s.n.m.

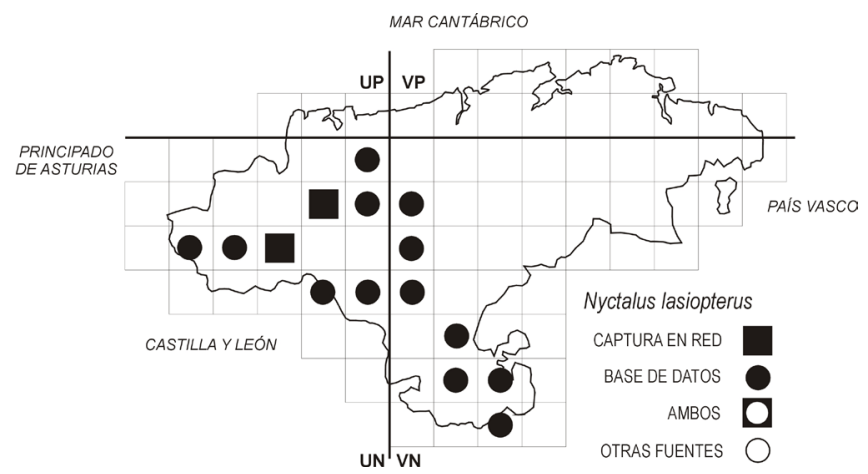

Fig. 25 - Distribución de Nyctalus lasiopterus en Cantabria según cuadrícula UTM de $100 \mathrm{~km}^{2}$. // Distribution of Nyctalus lasiopterus according to $100-\mathrm{km}^{2}$ UTM grid.

\section{Nóctulo común Nyctalus noctula Schreber, 1774}

Recientemente hemos confirmado la presencia de esta especie en Cantabria en base al análisis de grabaciones realizadas en cinco localidades, si bien sospechábamos su presencia desde hace muchos años en base a escuchas con detector y observaciones vespertinas. A diferencia de $N$. lasiopterus al cual observamos con regularidad en determinados enclaves boscosos y montañosos, grupos o ejemplares solitarios de $N$. noctula se localizan a lo largo de los ríos y sobre alumbrado nocturno de manera puntual, en localidades donde no vuelve a observarse hasta unas mismas fechas del siguiente año, lo que sugiere que se trate de ejemplares en movimientos dispersivos o paso migratorio, si bien no es descartable la existencia una población asentada (Alcalde et al. 2007) (Fig. 26).

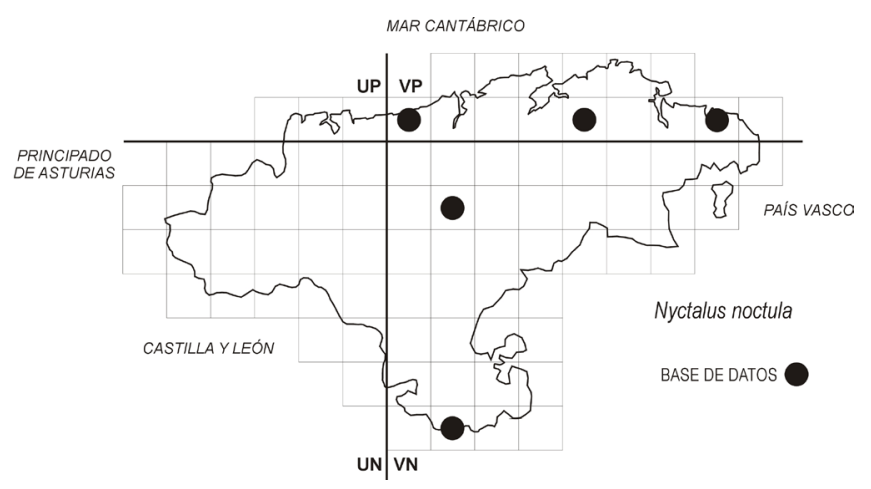

Fig. 26 - Distribución de Nyctalus noctula en Cantabria según cuadrícula UTM de $100 \mathrm{~km}^{2}$. // Distribution of Nyctalus noctula according to $100-\mathrm{km}^{2}$ UTM grid.

\section{Barbastela \\ Barbastella barbastellus Schreber, 1774}

Fue citado por primera vez por Lilford (1887), un pequeño grupo en la zona de Potes. Meijide (1982) lo cita en una cueva y cuatro parajes de bosque. Nada volvió a publicarse sobre esta especie en Cantabria hasta el presente, a excepción de Fombellida (2012b). En este manuscrito reportamos 125 registros en 71 localidades (Fig. 27), de los que 62 son capturas en red, cubriendo más de la mitad de la superficie regional. Habitan en todas las comarcas, desde la costa a la montaña, con registros entre 10 y 1.170 m s.n.m. . De 59 ejemplares sexados 29 fueron hembras y 30 machos, incluyendo ocho juveniles.

En consecuencia con lo anterior, los hábitat donde se ha detectado han resultado muy diversos: de 223 registros, el $87 \%$ fueron arbolados, un $10 \%$ parcialmente arbolados (campiña) y el resto desarbolados. Los bosques fueron de todo tipo, desde hayedos a encinares, y desde espesos a claros, destacando los robledales con un $40 \%$ del total, mientras que el arbolado ribereño estuvo presente en un $16 \%$ de los casos.

En cuanto a refugios, tenemos evidencia de un grupo reproductor (Fombellida et al. 2004), formado por unos 20 individuos, que ocupaban una contraventana de una casa junto a un robledal viejo de $Q$. pyrenaica con castaños (lugar que alternaban ocasionalmente con algún otro refugio). Y la captura de ejemplares que acudieron durante la noche a cuatro edificaciones del tipo cabaña o ermita, así como un túnel de una obra hidráulica.

Relativo a su reproducción, incluimos la colonia anterior, detectada en 2003 y que hasta 2008 ocupó el mismo lugar, momento en que las contraventanas que les albergaban fueron retiradas. Asimismo capturamos 21 hembras con indicios de reproducción en otras 11 localidades repartidas por toda la región. 


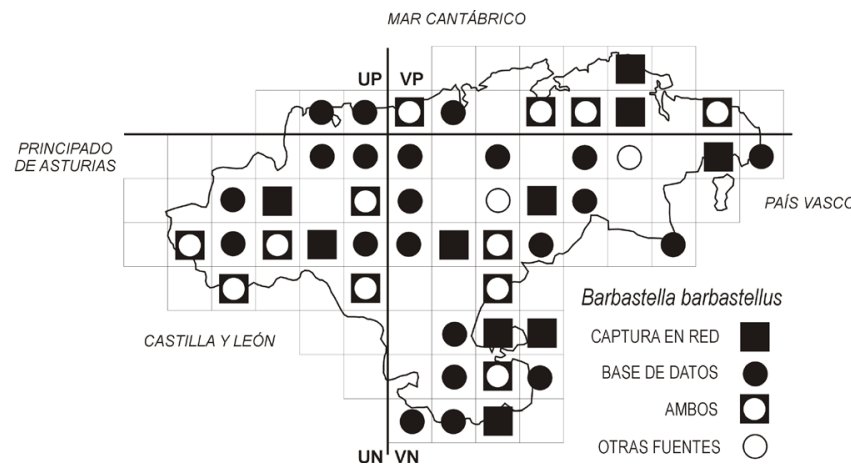

Fig. 27 - Distribución de Barbastella barbastellus en Cantabria según cuadrícula UTM de $100 \mathrm{~km}^{2}$. // Distribution of Barbastella barbastellus according to $100-\mathrm{km}^{2}$ UTM grid.

\section{Murciélago orejudo dorado Plecotus auritus Linnaeus 1758}

Meijide (1982) lo consideraba "solitario, no raro, poco abundante" en base a tan solo tres hallazgos de ejemplares en una cueva y un local urbano. No hay más citas hasta nuestros hallazgos en Liencres y Santander en 2008 (Saiz \& Fombellida 2008, Fombellida 2008b). Más adelante, la población de Liencres empezó a usar cajas-refugio que fueron instaladas para su mejor estudio y conservación (proyecto de la Asociación MUR, no publicado).

Contamos con 130 registros en 48 localidades (Fig. 28) (20\% de las prospectadas), de los que 107 son capturas en red (73 biopsias realizadas), y con análisis genético para 31 ejemplares de origen disperso por todo el área, todos ellos de la subespecie ibérica P. auritus begognae (De Paz 1994, Juste et al. 2004). El resto de los datos procede de individuos hallados en sus refugios o encontrados muertos. La razón de sexos para los ejemplares que fueron capturados fue de 51 hembras y 48 machos. De aquellas, al menos 36 mostraron signos de estar reproduciéndose. Nuestras observaciones se distribuyeron por la mitad del territorio, lo consideramos bastante común.

Ocupa una amplia variedad de hábitats, habiéndolo detectado desde el nivel del mar hasta 1.445 m s.n.m. Aproximadamente, la mitad de las localidades de observación correspondieron a ambientes forestales, destacando $Q$. pyrenaica con el $15 \%$ seguido de hayedos con $11 \%$, pero también $Q$. robur y plantaciones de Pinus pinaster y Pinus sylvestris (Entwistle et al. 1996). Los hábitats de campiña con setos y arbolado, las riberas y los parques urbanos, se hallaron bien representados. Entre los medios abiertos destacaron pastizales y brezales con el $10 \%$.

Relativo a sus refugios, se han observado en diversos tipos de construcciones, desde cabañas con paredes de madera, hasta grandes edificios abandonados, molinos, ermitas, cabañas de pastores, etc. También en cuevas. No hemos podido evaluar aún en qué medida utilizan árboles con huecos y otros refugios de origen no antrópico. Como ya hemos adelantado, en un pinar de Pinus pinaster de 50-60 años de antigüedad plantado sobre dunas costeras, donde la especie ya se hallaba presente al menos desde la década de 1980 (Tejedor, com. pers.), colocamos cajas-refugio en las que se albergó una colonia que hasta entonces contaba

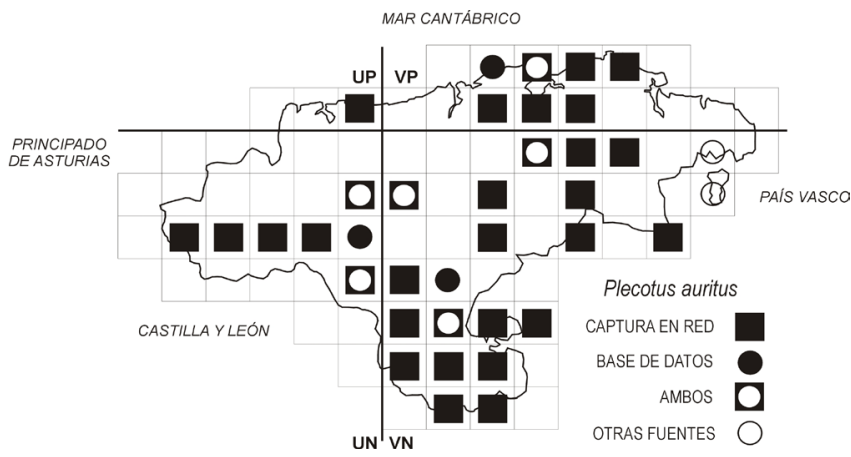

Fig. 28 - Distribución de Plecotus auritus en Cantabria según cuadrícula UTM de $100 \mathrm{~km}^{2}$. // Distribution of Plecotus auritus according to $100-\mathrm{km}^{2}$ UTM grid.

con opciones de refugio más precarias. En cada revisión se hallaron entre dos y cinco cajas ocupadas por 1-12 ejemplares cada una, sumando un máximo de 34 individuos, excepto en invierno cuando se ausentaban.

\section{Murciélago orejudo gris Plecotus austriacus Fischer, 1829}

Toca (2003a) reporta la primera cita de la especie por Rodríguez-Muñoz et al. (1993-94) durante la elaboración del Atlas de Vertebrados de Cantabria. Aparte de esto, la única información de que disponemos es la recogida de datos durante nuestras campañas de capturas con redes entre 2015 y 2017. Se obtuvieron 55 registros en 23 localidades (11\% de las prospectadas), de los que 50 son capturas, con análisis de ADN para cuatro individuos, cubriendo 14 cuadros UTM de $100 \mathrm{~km}^{2}$, lo que supone una quinta parte del territorio (Fig. 29). Dados los tipos de hábitat que ocupa y la dispersión de los contactos habidos, consideramos posible que se encuentre en un área mayor. El rango de altitudes observado oscila entre el nivel del mar hasta $1.590 \mathrm{~m}$ s.n.m., con media en 669. Las capturas realizadas han mostrado la misma distribución por altitudes que para $P$. auritus $(660$ m para $P$. auritus), excepto para una franja entre 400 y 700 m s.n.m., que pudiera corresponderse con las vertientes norte húmedas de la Cordillera Cantábrica, y que se aprecia en el mapa de la figura 30 en la forma de un patrón de distribución disjunto sobre el que habrá que profundizar en futuras prospecciones (Fernández et al. 2007). Estos datos se refieren a colectas a lo largo de todo el año, pudiendo quizá haber diferencias estacionales.

La razón de sexos para los ejemplares capturados fue de 30 hembras y 24 machos. Al menos 15 hembras mostraron signos de estar reproduciéndose.

Los hábitat han sido diversos, predominando la campiña (45\%) y los robledales de Quercus pyrenaica del Alto Ebro (18\%). Se precisan más datos para delinear posibles diferencias en selección de hábitat respecto $P$. auritus, así como los mecanismos de exclusión que les permiten coexistir (Ashrafi et al. 2013). Entre los refugios donde se realizaron las capturas destacaron viejos edificios como cuadras y pajares, iglesias, casas abandonadas, etc., y en menor medida cuevas. No hemos podido precisar hasta qué punto utilizan otro tipo de refugios al margen de los de origen antrópico. 


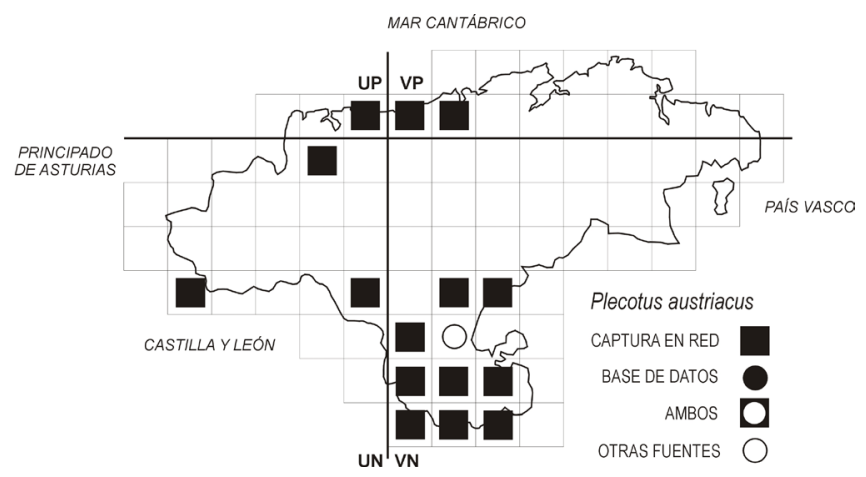

Fig. 29 - Distribución de Plecotus austriacus en Cantabria según cuadrícula UTM de $100 \mathrm{~km}^{2}$. // Distribution of Plecotus austriacus according to $100-\mathrm{km}^{2}$ UTM grid.

\section{Murciélago cavernícola Miniopterus schreibersii Kuhl, 1817}

Es uno de los taxones del que había información previa en forma de citas de ejemplares en cavidades subterráneas, pero sin precisar información relevante como su número, época del año en que ocupan dichos refugios o sexo de los ejemplares observados (Menéndez 1973, Meijide 1982, Tupinier 1982). Precisamente, este penúltimo cita 19 cavidades subterráneas con presencia de la especie en la región, lo que contrasta con las 106 cuevas dadas en el mismo catálogo con presencia de R. ferrumequinum. Ello muestra claramente la mayor selectividad de Miniopterus a la hora de elegir refugio, así como la concentración de sus poblaciones en unas pocas colonias (Blanco 1998, Palomo et al. 2007). De todas formas, probablemente numerosas cavidades con presencia comprobada posteriormente, donde no hay motivos para sospechar que se trate de ocupaciones recientes, no fueron detectadas. Por el gran tamaño observado entonces en las colonias, Meijide (1982) la consideraba una especie "común y abundante".

De las cuevas con presencia citadas por Meijide (1982) nueve han sido revisadas treinta años después: cuatro han sido cerradas perdiéndose las colonias (tres de ellas por contener yacimientos arqueológicos y la restante para una captación de agua); otras cuatro han visto muy reducido el número de ejemplares, estimamos en torno al 75\%; y en la restante solo hemos observado un ejemplar en una de las tres visitas realizadas. En otra cueva citada por Tupinier (1982) donde este autor señalaba una colonia reproductora que cubría "varios metros cuadrados de techo", en la temporada reproductora de 2017 solo hemos hallado 127 ejemplares, después de muchos años de acceso incontrolado de personas, promovido incluso desde la propia administración municipal. Dos de las cavidades citadas en el catálogo de Meijide (1982) que también acogen a otras especies cavernícolas, han sido declaradas LIC por el Gobierno de Cantabria (Menéndez 1973). Lamentablemente, dicha declaración no ha conllevado medidas reales de protección. En una de las cuevas se instaló un cierre perimetral que fue destruido a los pocos días, careciendo de vigilancia y protección. Y a la entrada de la otra cavidad, se abrió una ruta senderista muy concurrida haciéndola muy accesible, e incluso se construyó un acceso especial por medio de una escalera invitando a los paseantes a penetrar en la cueva,

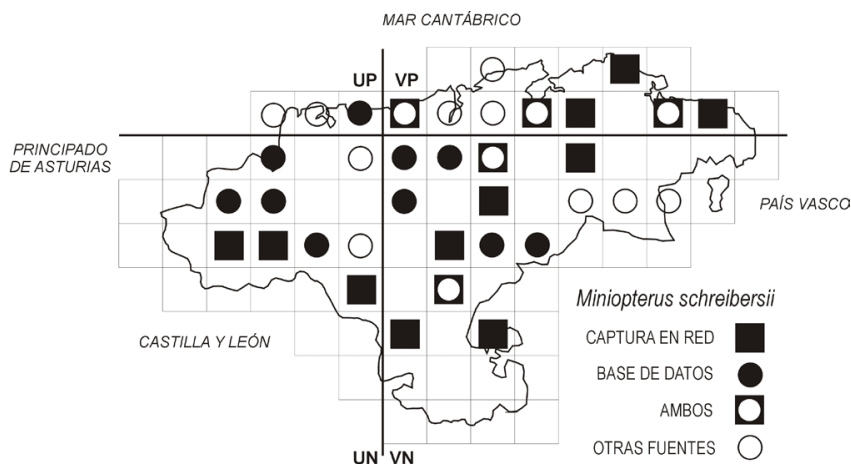

Fig. 30 - Distribución de Miniopterus schreibersii en Cantabria según cuadrícula UTM de $100 \mathrm{~km}^{2}$. // Distribution of Miniopterus schreibersii according to $100-\mathrm{km}^{2}$ UTM grid.

por lo que las imágenes de curiosos fotografiándose en ella y relatando sus experiencias es un hecho común en las redes sociales.

Posteriormente a lo publicado por Meijide (1982), González (2016) encontró a $M$. schreibersii presente en el $25 \%$ de las cavidades que prospectó, valorando su estado de conservación en riesgo (sin considerar las cavidades de las que la especie ya había sido excluida en el momento de hacer su estudio y que no entraron en su valoración). Entre las medidas de conservación propuestas en este documento, solo el censo de algunas colonias y eventuales desbroces para mantener despejada la boca de las cuevas han sido realizados.

En nuestro estudio hemos reunido 94 registros de 38 localidades (Fig. 30). De ellos, 54 son capturas en redes de niebla, y de los restantes, la mayor parte corresponden a grupos ocupando 15 cuevas, en cinco de las cuales encontramos evidencias de reproducción. De las capturas, solo 18 se produjeron en la entrada de refugios en tiempo post-reproductor, ya que se evitó trampear en refugios por considerarlo innecesario. Dichas observaciones cubren una zona algo inferior a la mitad del territorio, si bien la especie parece estar presente en todo el área de estudio aunque restringida a un número limitado de cavidades subterráneas como refugio. El rango de altitudes para el conjunto de nuestras observaciones ha variado entre el nivel del mar y 1.260 m s.n.m. De los ejemplares sexados 26 fueron hembras y 21 machos. Cinco de las hembras mostraban signos de reproducción.

Los refugios observados corresponden a cuevas que albergan entre 1 y 1.020 ejemplares, si bien la mayoría estaban ocupadas por entre uno y 30 individuos. Ocho cuevas concentraron más del $70 \%$ de la población, de las que en cuatro se reproduce, una es de invernada, y cuatro son ocupadas en sus desplazamientos o durante el celo.

En 2001, Toca (2001) lanzó una pregunta en un foro acerca de posibles causas para una mortandad masiva de ejemplares de quirópteros en una cavidad de Cantabria, citando de nuevo el hecho en una publicación sobre las cuevas de Villaescusa. Al año siguiente, mientras censábamos la colonia de El Calero, detectamos pocos individuos en salida vespertina, por lo que accedimos al interior de la cueva hallando numerosos ejemplares adultos muertos, así 
como embriones. Especialistas de la SECEMU reportaron resultados similares en muchas colonias peninsulares, lo que fue publicado por Quetglas et al. (2003). Los estudios subsiguientes llevaron a la determinación del virus "Lloviu cuevavirus" (Negredo et al. 2011), como agente causante de la mortandad. Estimamos que en Cantabria afectó a dos tercios de la población, en base a los recuentos en emergencia vespertina que veníamos haciendo en dos cavidades.

\section{Murciélago rabudo Tadarida teniotis Rafinesque, 1814}

Toca (2003a) refiere su localización mediante detectores por Rodríguez-Muñóz et al. (1993-1994) en sus prospecciones para el Atlas de Vertebrados de Cantabria. Posteriormente lo identificamos mediante detectores de ultrasonidos en las comarcas del oeste y sur, con poblaciones estables en el valle del río Deva (valle de Liébana), y Alto Ebro (Campoo, Valdeprado del Río y Valderredible). Escuchas más escasas pero repetidas en otros puntos parecen sugerir pequeñas poblaciones, como en el alto Asón (Cantabria oriental) y el valle del Saja, mientras que escuchas ocasionales en otras zonas son probablemente debidas a desplazamientos puntuales de amplio rango (alto Pas o bajo Saja). Parece ausente en la franja costera, incluidos los acantilados marinos, macizos calcáreos costeros y poblaciones.

Hemos reunido 68 registros de 48 localidades distribuidas por un tercio de la superficie regional (Fig. 31). Al ocupar zonas interiores, las altitudes en que se halló resultan elevadas, con registros desde 290 m s.n.m. en el desfiladero de La Hermida hasta 1.681 m s.n.m. en el collado de Llesba. La mayor parte de los contactos fueron de ejemplares solitarios, aunque también tenemos registros de pares de ejemplares volando juntos, detectándose grupos tan solo cerca de sus refugios (actividad de caza e interacción social). El 73\% de las observaciones fueron en hábitats abiertos, destacando la campiña montana y la campiña del Alto Ebro con un $19 \%$ de los registros, los roquedos con un $15 \%$, y los pastizales montanos con un $13 \%$. El $14 \%$ de los contactos sucedieron sobre poblaciones (pequeñas aldeas en zonas de montaña y del Alto Ebro), donde esta especie caza por encima del alumbrado nocturno. En el $27 \%$ de los casos los ejemplares fueron detectados sobre ambientes forestales, destacando los robledales de Quercus pyrenaica con un 13\% de los registros. Estos ambientes cubren gran extensión en

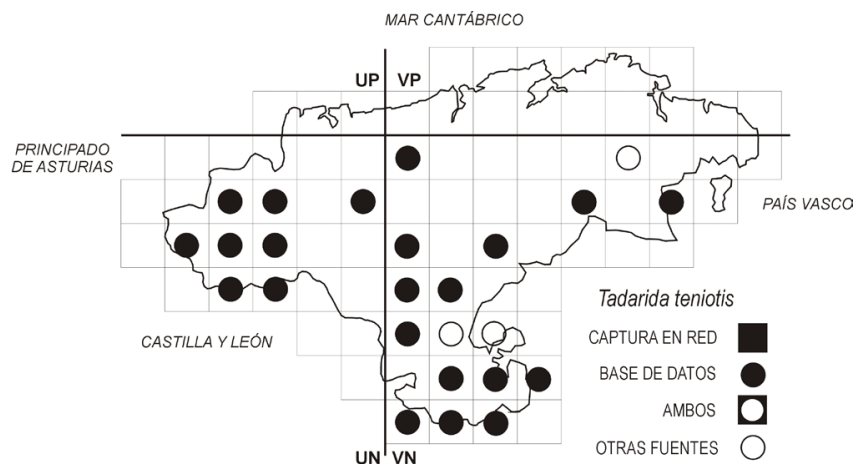

Fig. 31 - Distribución de Tadarida teniotis en Cantabria según cuadrícula UTM de $100 \mathrm{~km}^{2}$. // Distribution of Tadarida teniotis according to $100-\mathrm{km}^{2}$ UTM grid. los valles del Deva y el Ebro, donde se concentra la mayor parte de la población de la especie.

Respecto a sus refugios, hasta el momento solo han sido ubicados en cortados rocosos como el Desfiladero de La Hermida, el macizo oriental de los Picos de Europa y los cañones del Ebro, en base a vocalizaciones y vuelos vespertinos. Se ha detectado actividad en esta especie a lo largo de todo el año, incluso bajo condiciones climatológicas adversas como niebla y frío.

\section{AGRADECIMIENTOS}

Expresamos nuestro agradecimiento a los técnicos de la Dirección General de Biodiversidad del Gobierno de Cantabria por los permisos y facilidades dadas para la totalidad de actividades consideradas para este estudio. Así como a Ecologistas en Acción de Cantabria por su generosa aportación económica que MUR ha dedicado a la adquisición de material para continuar el proyecto. A la Estación Biológica de Doñana del CSIC, en las personas de Carlos Ibañez y Javier Juste, su ayuda durante nuestros trabajos, tanto en los trámites administrativos como aportando material, y por los análisis de ADN que han permitido situar a las especies crípticas de Cantabria en el mapa. Así como al personal de la EBD desplazado a Cantabria, y todos aquellos que han compartido jornadas de campo y sus conocimientos con nosotros: Roberto Novella, Pedro Alonso, Daniel Fernández, Carmen Soria, Roberto Hermida, Paulo Barros, Helena Dos Santos, Anabel Casáis, David García, Juan Tomás Alcalde, Félix González-Álvarez y Mariano Luis Serna. Sin olvidar a todos los socios de MUR, sin cuyo empuje no serían posibles estos trabajos en beneficio de la fauna quiropterológica de Cantabria, especialmente Álvaro González, Javier Aizcorbe, Sara Moreno, Miguel Oscar García y Máximo Sánchez.

\section{REFERENCIAS}

AGUIRRE-MENDI, P. T. \& IBÁÑEZ, C. (2012). Primeros datos sobre la distribución de Myotis cf. nattereri y Myotis escalerai Cabrera, 1904 (Chiroptera: Vespertilionidae) en la Comunidad Autónoma de La Rioja. Barbastella. 5 (1): 8-11. https://doi.org/10.14709/BarbJ.5.1.2012.02

ASHRAFI, S., RUTISHAUSER, M., ECKER, K., OBRIST, M. K., ARLETTAZ, R. \& BONTADINA, F. (2013). Habitat selection of three cryptic Plecotus bat species in the European Alps reveals contrasting implications for conservation. Biodivers and Conservation. https://doi.org/10.1007/ s10531-013-0551-z

BALCELLS, E. (1964). Sobre Nuevas Citas de Mamíferos de la Península Ibérica. Bol. R. Soc. Esp. Hist. Nat. Sec. Biol., 62: 367-368.

BARATAUD, M. (1995). The world of bats: Acoustic identification of French bats. Sittelle publisher, Mens, France, $47 \mathrm{pp}$.

BARATAUD, M. (2015). Ecologie acoustique des chiroptères d'Europe. Biotope, Mezè; Muséum National d'Historie naturalle, Paris, France,352 pp. 
BENZAL, J. \& DE PAZ, O. (1991). Los Murciélagos de España y Portugal. Colección Técnica. ICONA, 342 pp.

BLANCO, J.C. (1998). Mamíferos de España. Planeta, Barcelona, España, 457 pp.

BOGDANOWICZ, W. (1990). Geographic Variation and Taxonomy of Daubenton's Bat, Myotis daubentonii in Europe. Journal of Mammalogy, 71 (2): 205-218.

DE PAZ, O. (1994). Systematic position of Plecotus (Geoffroy, 1818) from the Iberian Peninsula (Mammalia: Chiroptera). Mammalia, 58: 423-432.

DIETZ, C. \& VON HELVERSEN, O. (2004). Illustrated identification key to the bats of Europe. Tübingen, Germany, 72 pp.

DIETZ, M., ENCARNAÇÃO, J. A. \& KALKO, E. K. V. (2006). Small scale distribution patterns of female and male Daubenton's bats (Myotis daubentonii). Acta Chiropterologica, 8(2): 403-415. https://doi. org/10.3161/1733-5329(2006)8[403:SSDPOF]2.0.CO;2

ENTWISTLE, A. C., RACEY, P. A., \& SPEAKMAN, J. R. (1996). Habitat exploitation by a gleaning bat, Plecotus auritus. Phil. Trans. R. Soc. B., 351:921-931. https://doi. org/10.1098/rstb.1996.0085

FERNÁNDEZ, J. (2002). Los Murciélagos de Castilla y León: Atlas de distribución y tamaño de las poblaciones. Junta de Castilla y León, Consejería de Medio Ambiente, 343 pp.

FOMBELLIDA, I., FELICÍSIMO, A. M., FERNÁNDEZ, J. M., FRANCÉS, E., GOMEZ, A., CORRAL, D., SANCHEZ, M., \& SALAS, L. (2004). Cartografía de la Distribución Potencial de Aves y Mamíferos en los LIC de Liébana y Rías Occidentales de Cantabria. DCITIMAC, Universidad de Cantabria. Informe inédito para la Dirección General de Montes y Conservación de la Naturaleza de Cantabria.

FOMBELLIDA, I. (2005). Inventario de Especies de Fauna Vertebrada en el Valle del arroyo Carranquío (Sierra de Ibio-Mazcuerras). Informe inédito para la Junta Vecinal de Sierra de Ibio.

FOMBELLIDA, I. (2006). Inventario de Especies de Fauna Vertebrada (Anfibios, Reptiles, Aves y Mamíferos) en el Macizo del Monte Dobra. Documento inédito para la asociación "Ecologistas en Acción".

FOMBELLIDA, I. (2008a). Propuesta de Espacios a Conservar, para la Protección de Fauna Vertebrada Terrestre (Anfibios, Reptiles, Aves y Mamíferos), en el Municipio de Santa Cruz de Bezana. Infogrme inédito para la Dirección General de Medio Ambiente de la Consejería de Medio Ambiente del Gobierno de Cantabria.

FOMBELLIDA, I. (2008b). Inventario de Especies de Fauna Vertebrada (Anfibios, Reptiles, Aves y Mamíferos) en los Jardines de La Magdalena (Santander). Plan Director de La Magdalena. Documento inédito del Ayuntamiento de Santander y el DCITIMAC de la Universidad de Cantabria.
FOMBELLIDA, I. \& SAIZ, J. (2009). Apoyo a la Elaboración de Inventario y Propuesta de Actuaciones para la Recuperación de la Fauna Vertebrada en el Macizo de Peña Cabarga. Informe inédito de Mustela S. C. para la Dirección General de Biodiversidad de la Consejería de Desarrollo Rural, Ganadería, Pesca y Biodiversidad de Cantabria.

FOMBELLIDA, I. (2012a). Estudio de la Presencia de Quirópteros en el Parque Eólico Proyectado de La Matanela, Municipio de Luena, Cantabria. Informe inédito para Biocantaber S. L.

FOMBELLIDA, I. (2012b). Muestreo de Quirópteros en la Franja Costera Occidental de Cantabria. Maresía, Cuadernos de Naturalistas Cantábricos, 3: 4-20.

GOBIERNO DE CANTABRIA. Decreto 120/2008, de 4 de diciembre por el que se regula el Catálogo Regional de Especies Amenazadas de Cantabria, BOC - № 249, p. 17608.

GOITI, U. \& AIHARTZA, R. (2005). Rhinolophus euryale (Blasius, 1853). Murciélago mediterráneo de herradura. En Atlas de los Mamíferos Terrestres de España, Ministerio de Medio Ambiente (DGB-MIMAM). Gobierno de España, pp: 130-133.

GONZÁLEZ, C. (2016). Realización de estudios específicos para la redacción de los planes de gestión de los espacios de la Red Natura 2000 en Cantabria. Consejería de Ganadería, Pesca y Desarrollo Rural. Gobierno de Cantabria.

GONZÁLEZ-ÁLVAREZ, F. \& RODRÍGUEZ-MUÑOZ, R. (1995) Distribution of bats in Asturias (Northern Spain). Myotis, 32-33: 163-181.

IBÁÑEZ, C., GARCÍA-MUDARRA, J.L., RUEDI, M., STADELMANN, B., JUSTE, J. (2006). The Iberian contribution to cryptic diversity in European bats. Acta Chiropterologica, 8: 277-297. https://doi. org/10.3161/1733-5329(2006)8[277:TICTCD]2.0.CO;2

JUSTE, J., C. IBÁÑEZ, J. MUÑOZ, D. TRUJILLO, P. BENDA, A. KARATAŞ, AND M. RUEDI. (2004). Mitochondrial phylogeography of the long-eared bats (Plecotus) in the Mediterranean Palaearctic and Atlantic Islands. Molecular Phylogenetic and Evolution, 31: 1114-1126. https://doi.org/10.1016/j.ympev.2003.10.005

LILFORD, L. (1887). A few words on European bats. The Zoologist,3(11): 61- 67.

LUČAN, R. K. \& HANÁK, V. (2011). Population ecology of Myotis daubentonii (Mammalia: Chiroptera) in South Bohemia: summary of two long-term studies: 19681984 and 1999-2009. Acta Soc. Zool. Bohem. 75: 67-85, 2011.

MEIJIDE, M. (1982). Catálogo de los Quirópteros de la Provincia de Santander (España). Cuadernos de Espeleología, 9-10: 101-112. 
MENÉNDEZ, R. (1973). Cinecología de la Cueva del Calero (Oreña, Santander). Cuadernos de Espeleología 7: 61-82.

NEGREDO, A., PALACIOS, G., VÁZQUEZ-MORÓN, S., GONZÁlEZ, F., DOPAZO, H., MOLERO, F., JUSTE, J., QUETGLAS, J., SAVJI, N., DE LA CRUZ MARTÍNEZ, M., HERRERA, J.E., PIZARRO, M., HUTCHISON, S.K., ECHEVARRÍA, J.E., LIPKIN, W.I. \& TENORIO, A. (2011). Discovery of an Ebolavirus-Like Filovirus in Europe. PLOS Pathogens, 7(10): e1002304. https://doi.org/10.1371/ journal.ppat.1002304

OBRIST, M. K., BOESCH, R. \& FLÜCKIGER, P. F. (2004). Variability in echolocation call design of 26 Swiss bat species: consequences, limits and options for automated field identification with a synergetic pattern recognition approach. Mammalia, 68 (4): 307-322. https://doi. org/10.1515/mamm.2004.030

PALOMO, L. J., GISBERT, J. \& BLANCO, J. C. (2007). Atlas y Libro Rojo de los Mamíferos Terrestres de España. Dirección General para la Biodiversidad-SECEM-SECEMU, Madrid, $586 \mathrm{pp}$.

QUETGLAS, J., GONZÁLEZ, F. \& DE PAZ, O. (2003). Estudian la Extraña Mortandad de Miles de Murciélagos de Cueva. Quercus, 203: 50.

RIVAS-MARTíNEZ, S. (1983). Pisos Bioclimáticos de España. Lazaroa, 5: 33-43.

ROdRígueZ-MUÑóZ, R., GONZÁLEZ, F., PÉREZ, F. J. \& ALCALDE, J. T. (1993-1994). Observaciones de Pipistrellus nathusii (Keyserling \& Blasius, 1839) (Chiroptera, Vespertilionidae) en la Península ibérica. Arxius de Miscel·lània Zoològica, 17: 205-211.

RUSSO, D. \& JONES, G. (2002). Identification of twentytwo bat species (Mammalia: Chiroptera) from Italy by analysis of time-expanded recordings of echolocation calls. Journal of zoology, 258(1): 91-103. https://doi. org/10.1017/S0952836902001231

SAIZ, J. \& FOMBELLIDA, I. (2006). Inventario de Fauna Vertebrada del Parque Natural de Oyambre. Informe inédito de Mustela S. C. para la Dirección General de Montes y Conservación de la Naturaleza de Cantabria.
SAIZ, J. \& FOMBELLIDA, I. (2008). Inventario de Fauna Vertebrada en los Espacios Naturales de Liencres, Estuario del Pas y Costa Quebrada. Informe inédito de Mustela S. C. para la Dirección General de Biodiversidad de la Consejería de Desarrollo Rural, Ganadería, Pesca y Biodiversidad de Cantabria.

SALICINI, I., IBÁÑEZ C. \& JUSTE J. (2011). Multilocus phylogeny and species delimitation within the Natterer's bat species complex in the Western Palearctic. Molecular Phylogenetics and Evolution. 61: 888-898. https://doi. org/10.1016/j.ympev.2011.08.010

SALICINI, I., IBÁÑEZ C. \& JUSTE J. (2012). El complejo Myotis nattereri en Iberia: una larga historia. Barbastella 5(1): 3-7. https://doi.org/10.14709/BarbJ.5.1.2012.01

SCHOBER, W. \& GRIMMBERGER, E. (1987). Die Fledermäuse europas. Franckh-Kosmos-Verlags-GmbH \& Co., Stuttgart, Germany, 265 pp.

SIMOES, B. F., REBElO, H., LOPES, R. J., ALVES, P. C. \& HARRIS, D. J. (2007). Patterns of genetic diversity within and between Myotis $d$. daubentonii and M. $d$. nathalinae derived from cytochrome $b$ mtDNA sequence data. Acta Chireptologica, 9(2): 379-389. https://doi. org/10.3161/1733-5329(2007)9[379:POGDWA]2.0.CO;2

TOCA, M. A. (2001). Los Murciélagos de las Cuevas de Villaescusa. En: Las Cuevas de Villaescusa. Asociación de Patrimonio del Valle de Villaescusa, ACDPS \& Consejería de Cultura y Deporte del Gobierno de Cantabria.

TOCA, M. A. (2003a). Los Murciélagos Cavernícolas en Cantabria: Una Revisión. Boletín Cántabro de Espeleología, 15: 89-98.

TOCA, M. A. (2003b). Nuevos Datos Sobre la Ecología de los Murciélagos en Cantabria. Locustella 2: 114-117.

TUPINIER Y. (1977). Description d'une chauve souris nouvelle: Myotis nathalinae nov. sp. (ChiropteraVespertilionidae). Mammalia, 41(3): 327-340.

TUPINIER, Y. (1982). Quirópteros de España, Sistemática y Biogeografía. Cuadernos de Espeleología, 9-10: 217-240. Santander.

VALVERDE, J.A. (1953). Notas sobre Murciélagos. Munibe, 5: $240-2$. 